\title{
Working
}

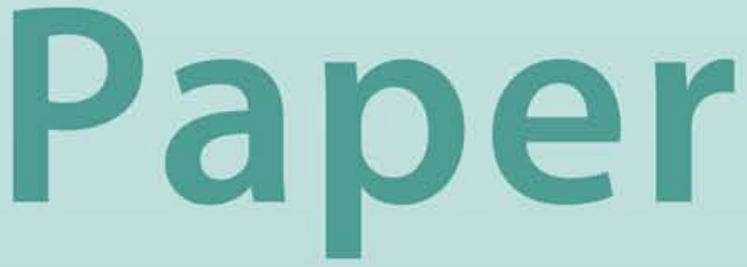




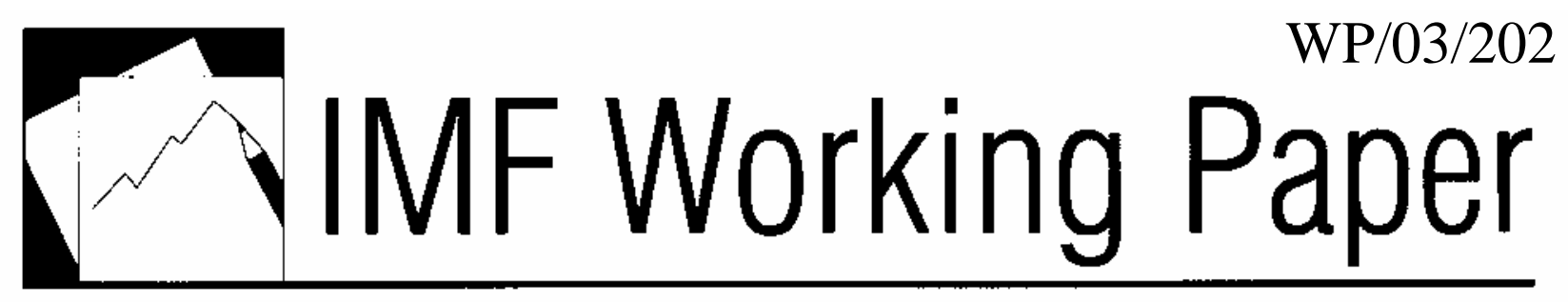

\section{Pricing Debit Card Payment Services: An IO Approach}

Wilko Bolt and Alexander F. Tieman 


\title{
IMF Working Paper
}

\author{
International Capital Markets Department
}

\section{Pricing Debit Card Payment Services: An IO Approach}

\author{
Prepared by Wilko Bolt and Alexander F. Tieman ${ }^{1}$ \\ Authorized for distribution by David J. Ordoobadi
}

October 2003

\begin{abstract}
The views expressed in this Working Paper are those of the author(s) and do not necessarily represent those of the IMF or IMF policy. Working Papers describe research in progress by the author(s) and are published to elicit comments and to further debate.
\end{abstract}

This paper presents a theoretical framework for analyzing pricing structures in debit card schemes featuring cardholders, retailers, their respective banks, and a network routing switch. The network routing switch controls the electronic debit card network and is jointly owned by the banks. In setting its prices, it needs to consider getting both consumers and retailers to participate in the market. In this two-sided market for debit cards, we show that the "double-monopolistic" network routing switch may want to supply consumers with cheap debit cards, deriving profits from charging a high retailer fee per transaction. This theoretic result resembles the current practice in the Netherlands where consumers pay no transaction fee, but retailers do. This corner solution carries over when we analyze socially optimal pricing.

JEL Classification Numbers: G21, L10, L41

Keywords: Debit card payment systems, two-sided monopolistic pricing, social optimum Authors’ E-Mail Addresses: w.bolt@dnb.nl, atieman@imf.org

\footnotetext{
${ }^{1}$ Wilko Bolt is with De Nederlandsche Bank (the Dutch central bank). Alexander Tieman is with the IMF. The authors thank Peter van Els and participants of the 2003 European Finance Association conference in Glasgow for helpful comments. The views expressed in this paper do not necessarily represent those of De Nederlandsche Bank or the European System of Central Banks.
} 


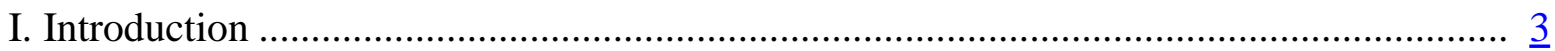

II. Related Literature on Payment Card Schemes ................................................. $\underline{5}$

III. Debit Card Schemes with Delegated Acquiring: the "Dutch" Model ........................... $\underline{8}$

A. The Debit Card Model .............................................................................. $\underline{8}$

B. Double Monopoly, Two-Sidedness, and Pricing Strategy ................................

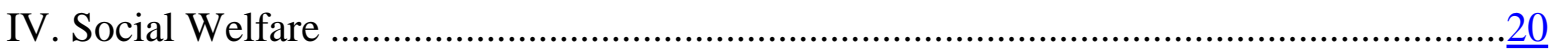

A. Examining the Social Welfare Function .......................................................

B. Balanced Budget Fees ........................................................................

V. Some Thoughts on System Competition.............................................................29

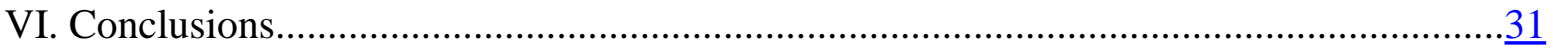

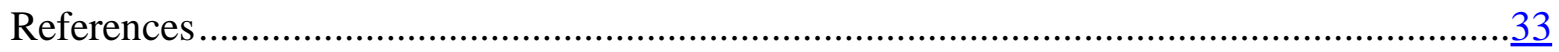

Tables

1. Uniform Distribution: Prices and Profits .............................................................. $\frac{15}{19}$

2. Constant Elasticity Distribution: Prices and Profits................................................. $\frac{19}{23}$

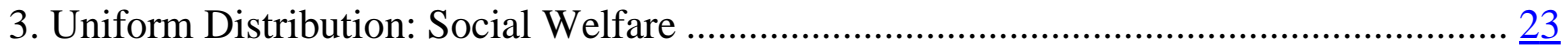

4. Constant Elasticity Distribution: Social Welfare ................................................... 26

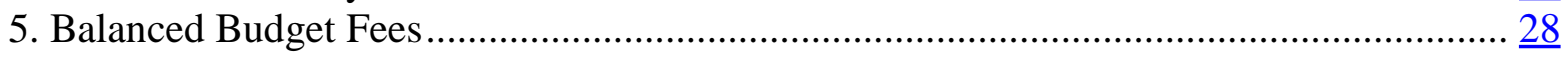

Figures

1. The International Model: Pricing in a Four-Party Card Scheme ................................ $\underline{5}$

2. The "Dutch" Debit Card Model: Delegated Acquiring ................................................ 9

3. Profits under a Uniform Distribution: Global Maximum ............................................ $\frac{17}{20}$

4. Profits under a Constant Elasticity Distribution .................................................... $\frac{20}{20}$

5. "Corner" Social Welfare Functions ........................................................................ $\frac{27}{30}$

6. System Competition in a Debit Card Network ......................................................... $\underline{30}$ 


\section{INTRODUCTION}

The international payment landscape is changing rapidly. The fast growth of credit and debit card payment systems in many modern economies is perhaps one of the most striking examples of this. Chang and Evans (2000) calculate that in the United States alone in 1998, consumers used their payment cards to charge around one trillion U.S. dollars. Based on data from the Bank for International Settlements (BIS) and the European Central Bank (ECB), Kreuger (2001) estimates that in 12 industrial countries the use of debit and credit cards rose from 9.3 billion transactions in 1987 to 33.7 billion transactions in $1998 .^{2}$ In particular, in the Netherlands, the enormous upswing in the usage of debit cards has been the main driver for the rapid developments in noncash payments. Debit card payments in the Netherlands exceeded EUR 50 billion in 2002 (around 11 percent of GDP) - with a volume of over one billions debit card transactions, more than 40 times higher than in 1991 - and are still growing rapidly ${ }^{3}$. However, payment systems and services are not free. In fact, they impose high resource costs on society. To illustrate, it has been estimated that in 1995, the United States spent 3 percent of its GDP just to make payments; see Humphrey, Pulley, and Vessala (2000). ${ }^{4}$ It is therefore important that payment systems satisfy some basic principles of economic efficiency.

Undoubtedly, the widely observed shift from the use of cash toward electronic modes of payment has led to an increase in the overall efficiency of (retail) payment systems. Still, non-transparent, and possibly inefficient, pricing arrangements for payment cards have attracted controversy and triggered antitrust scrutiny. Very recently, a federal antitrust lawsuit brought by U.S. retailers against Visa and MasterCard regarding their debit card practices resulted in an out-of-court settlement involving compensation payments of about 3 billion U.S. dollars by the two major credit card companies. Also, the European Commission (2000) has been analyzing interchange fees and the rules set by the members of credit card associations. In Germany, recently, a lively debate has come to the fore on the adoption of a common interchange fee for all debit card payments. Further, in the Netherlands, retailers have expressed their dissatisfaction with some parts of the Dutch payment system, especially drawing attention to current pricing and acquiring arrangements for debit card services. Many of the Dutch retailers' complaints involved perceived monopolistic behavior by Interpay, the central routing switch in the nationwide debit card network that is owned by Dutch banks, in terms of pricing policies, transparency, and delivered quality of services. ${ }^{5}$ Clearly, pricing issues concerning card payment services are interesting and warrant theoretical analyses.

\footnotetext{
${ }^{2}$ These 12 countries are Belgium, Canada, Denmark, Finland, France, Germany, Italy, the Netherlands, Sweden, Switzerland, the United Kingdom, and the United States.

${ }^{3}$ In contrast, in the Netherlands the usage of credit cards is very limited. About $0.5 \%$ of non-cash payments are made using credit cards. See www.dnb.nl for more data on Dutch payment systems.

${ }^{4}$ Other studies show similar results for different countries with cost estimates in the range of $1 \%-3 \%$ of GDP; see Bolt (2003) and the references therein.

${ }^{5}$ Triggered by these complaints of retailers, the Dutch Minister of Finance requested a thorough investigation into the infrastructure and tariff structures of the Dutch retail payments system, see Bolt (2003) for an overview.
} 
Pricing arrangements for debit card services are a complex matter, since electronic payment networks give rise to strong network externalities. Cardholders, retailers, and issuing and acquiring banks all have to cooperate in order to facilitate the card transaction. In particular, cardholders value debit cards only to the extent that these are accepted by retailers, while retailers, in turn, benefit from a widespread usage of cards. This is sometimes called the "chicken-and-egg problem" and points to the two-sided nature of the market for debit cards. In setting its prices, the central routing switch in the debit card network needs to be careful to get both consumers and retailers on board. "Two-sidedness" has major implications for the pricing structure used for debit cards, which will, in general, depend on price elasticities of demand of consumers and retailers. However, the theoretical analysis of two-sided markets has received little attention thus far. In a very elegant paper, Rochet and Tirole (2001) started to fill this gap.

Rochet and Tirole (2001) characterize the interior solution in a monopolistic two-sided market, which under log-concavity of the demand functions yields maximum total profits. They show that for the market as a whole, the well-known monopolistic Lerner pricing rule still holds: the more inelastic the market as a whole, the higher the total price. The way this total price is allocated between the two sides of the market depends on the relative magnitude of the individual market sides' price elasticities of demand. Here we observe a counterintuitive result, in the sense that the most elastic side is charged the highest fee. Compare this result with the case of a multiproduct monopolist with complementary products, where one would instead find a lower price for the more elastic market. Empirical evidence on payment data also points in this direction. Currently in the Netherlands, consumers pay no transaction fee for using their debit cards - only retailers pay such a fee. In the context of the analysis by Rochet and Tirole (2001), this would imply that consumer demand was either totally inelastic in absolute terms or much less elastic than that of retailers. In contrast, recent empirical studies have shown that consumers are quite sensitive to price changes of payment services (see, for example, Humphrey, Kim, and Vale (2001)).

As we will show below, under constant elasticity of demand, cardholders are effectively subsidized by retailers so as to boost the demand for debit cards. Effectively, consumers are charged the lowest admissible price, and retailers, since their demand for card services is assumed to be less elastic, pay a high fee. This theoretical result, which is mathematically characterized by a corner solution, corresponds nicely to the current practice of pricing debit card payments in the Netherlands. Qualitatively, this result carries over when one studies socially optimal pricing. When consumers are sufficiently more price elastic than retailers, it could be socially optimal to charge only retailers a relatively high fee for their use of debit card services, while consumers are charged only a minimum fee. We will also show that socially optimal prices are, in general, lower than the monopolistic prices set by the network switch. Accordingly, there is a tendency of the network switch to undersupply debit card services.

The remainder of the paper is organized as follows. In Section II we present a literature overview. Specifically, we focus on a model of electronic payment services including consumers, retailers, and their respective banks, which charge interchange fees. Such a setup is present in the retail payment systems of most countries, the United States in particular. We label this 
Figure 1. The International Model: Pricing in a Four-Party Card Scheme

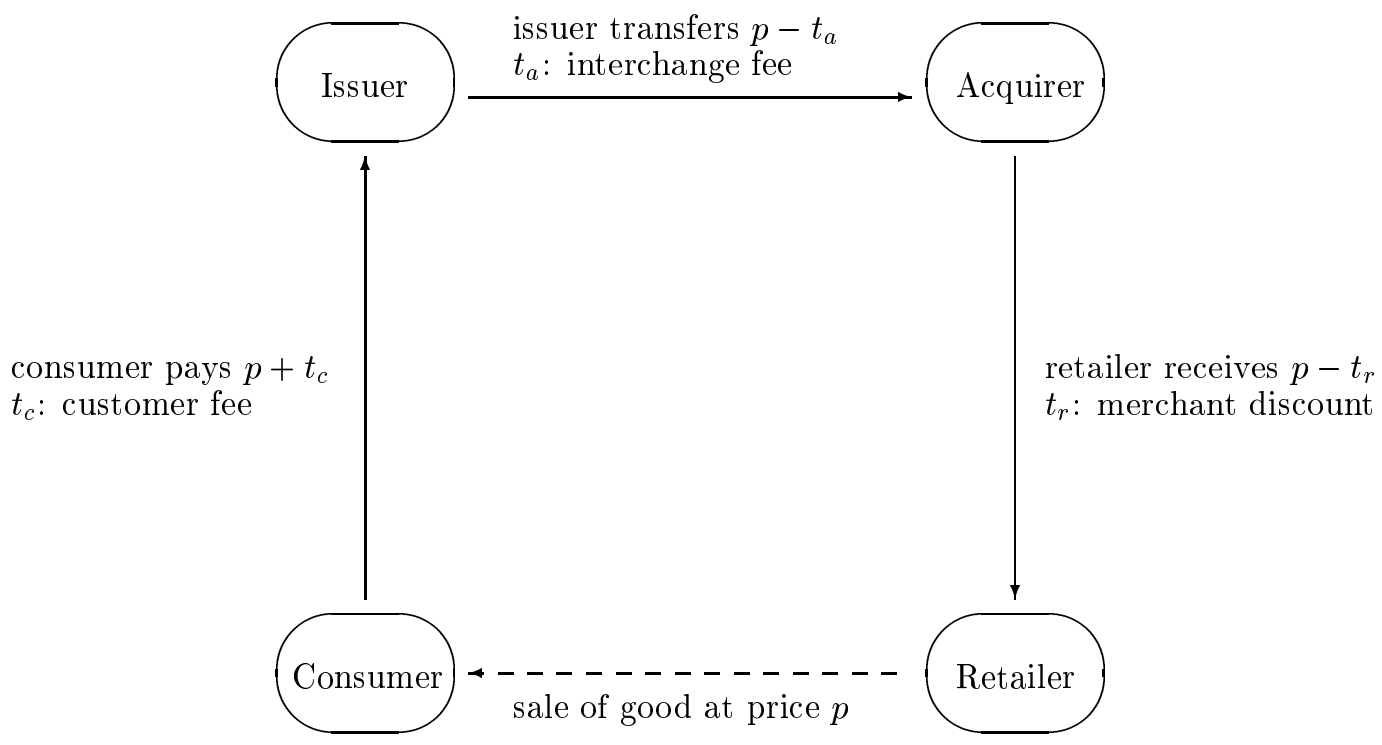

model the international model. Section III describes the Dutch debit card model, which includes an important role for a central routing switch that sets the prices for both consumers and retailers. In this model, we show that the lack of retailers' choice of payment service provision may lead to an overpricing of payment services for retailers. In Section IV we analyze socially optimal prices of the debit card system. It is shown that when socially optimal prices are implemented, the debit card network operates at a loss. Section V present some first thoughts on system competition in the debit card network, which occurs when another network switch enters the arena. Section VI concludes.

\section{Related Literature on Payment Card Schemes}

Pricing structures in payment card schemes have received scant attention in the literature. Most of the models described in the literature focus on "four-party" card schemes, because four parties are typically involved in the payment process. These parties are $i$ ) the consumer (or cardholder), ii) the issuer -the bank that issues the payment card to its customer-, iii) the aquirer - the bank that serves the retailer accepting the card for payment, and $i v$ ) the retailer. The flow of funds and fees in this four-player model, which we dub the "international model", is depicted in Figure 1.

When a transaction takes place, the consumer receives the good from the retailer at price $p>0$. After authorization and verification procedures the consumer's bank (the issuer) debits 
the consumer's account for an amount $p+t_{c}$, with $t_{c} \geq 0$ a charge by the issuing bank to the consumer. The issuing bank transfers the money minus an interchange fee $t_{a} \geq 0$ to the retailer's bank (the acquirer). The retailer's bank receives the amount $p-t_{a}$ and credits the retailer's account for an amount $p-t_{r}$, where $t_{r} \geq 0$ is the retailer's fee, also known as the "merchant discount".

This international model has been studied with emphasis on several different features. One of the earliest references is Baxter (1983) who analyses a competitive market for payment cards. Baxter notes that in a four-party scheme, there is no reason why both banks should break even at the social optimum where total net costs (i.e. the sum the issuer's and aquirer's net costs) equals total net benefits (i.e. the sum of the consumer's and retailer's net benefits). Loosely speaking, at this optimum the payment network has a zero-sum structure and the profit-making bank should compensate the loss-making bank in order to make the payment network attractive to all parties. The interchange fee may easily solve this problem by redistributing profits from one bank to another. Baxter's theory does not however predict the direction of the flow, it depends on the magnitude of relative costs and benefits of the four parties.

Rochet and Tirole (1999) take Baxter's analysis as a starting point and assume endogenous consumer and retailer behavior in a Hotelling (1929) style location model. They develop a formal model in which they examine the effects of interchange fees on social welfare and the possible anticompetitive nature of the so-called "no-surcharge" rule. ${ }^{6}$ The analysis mainly concerns one payment card association and a single alternative payment mechanism, say cash. Aquiring is assumed to be competitive and a variety of market structures for issuing is considered. Many of the results are driven by the fact that the payment card association tries to exploit the retailer's eagerness to get a competitive edge over his competitors by accepting payment cards. The paper shows that when a no-surcharge rule is in effect, and if the total cost of issuing and acquiring is sufficiently low, a credit card association may set an interchange fee that leads to overprovision of credit card services. In this case, the monopoly incentive to provide less card services is more than compensated by the low amount of retailer resistance and the associated high fees. Otherwise, if total cost of issuing and aquiring is high then both privately and socially optimal interchange fees are equal to the highest level consistent with retailer acceptance of cards.

These conclusions change when the no-surcharge rule is lifted. Then, retailers will charge cardholders a higher price than non-cardholders. Such retailer price discrimination could lead to an underprovision of card services. Further, retailer resistance to card acceptance is influenced by the degree of competition in the retail market. With increased competition, that is, through better consumer information about which stores accept the card or a higher consumer willingness to leave a store when it does not accept the card, retailer resistance

\footnotetext{
${ }^{6}$ The no-surcharge rule states that affiliated merchants are not allowed to impose surcharges on customers who pay with a card.
} 
diminishes. System competition however, increases retailer resistance when some consumers carry multiple cards from different associations. ${ }^{7}$

A drawback of the analysis by Rochet and Tirole (1999) is that they neglect the network externalities involved in payment services. When many consumers use cards, the retailer benefits of accepting a card increase. Likewise, when many retailers accept the card, consumer benefits of carrying one increase. This so-called "chicken-and-egg" dilemma is incorporated by Schmalensee (2001). In a model of credit card associations Schmalensee incorporates these externalities by specifying total demand for payment services as a multiplication of underlying partial merchant and consumer demands. Both types of underlying demand are increasing in the other side's usage of the payment system. The paper focuses on issues associated with interchange fees in payments systems. Schmalensee notes the double marginalization problem which arises when there is market power on both the issuing and acquiring side of the market. Indeed the acquirer, which pays an interchange fee to the issuer, does not take the additional profit of the issuer from an additional transaction into account when setting the merchant discount. This problem cannot be solved by interchange fees as it arises naturally in any vertical structure with market power in both segments. The only solution seems to be the introduction of a proprietary payment card system, in which the issuer and acquirer are the same firm, or the mitigation of market power on either side of the market.

By specifying a general demand structure, Schmalensee is able to draw welfare conclusions from his analysis. When total system profits (the sum of issuer and acquirer profits) are jointly maximized and demand is linear, the optimal interchange fee maximizes total system output and total social welfare. Moreover Schmalensee (2001) indicates that proprietary card systems generate distinctly lower total output than cooperative card associations if competition in issuing and acquiring is vigorous. Thus, in this case, the same conclusion as in Rochet and Tirole (1999) holds: interchange fees do not cause underprovision of payment services. These results indicate that there is no theoretical motivation for antitrust authorities to condemn collective determination of interchange fees. Interchange fees are not like ordinary market prices. Instead they are a balancing device for shifting costs between issuers and acquirers and thus shifting charges between consumers and retailers.

Another interesting paper on payment activity concerns the analysis by Schwartz and Vincent (2002), where the focus is again on the role of interchange fees under the no-surcharge rule. Their model however abstracts from consumer cardholding decisions: some consumers use cash, others use cards, and this distribution is fixed. Schwartz and Vincent show that a no-surcharge rule lowers total welfare when the issuing side is competitive and demand for retailer goods is linear. Although a no-surcharge rule lowers the net price paid by cardholders and raises it for non-cardholders, the welfare losses outweigh the gains. Similar results are found in Gans and King (2001b) where the authors characterize the socially optimal interchange fee level. In an

\footnotetext{
${ }^{7}$ See Wright (2001) for a closely related model.
} 
accompanying article, Gans and King (2001a) prove a robust "neutrality result" by showing that in the absence of a no-surcharge rule, interchange fees can never have any real effects, irrespective of the level of competition at either the bank or the retailer level. They further show that in the presence of a no-surcharge rule, interchange fees cannot be manipulated in a profitable manner if there is adequate competition from "cash only" retailers.

\section{Debit Card Schemes with Delegated Acquiring: THE "DUTCH" MODEL}

Most of the literature on non-cash payment activity draws attention to the analysis of credit card networks. However, over the last decade many countries have shown a rapid increase in the usage of debit cards. To avoid an abundance of costly bilateral agreements and procedures between financial institutions and banks, debit cards schemes often show a fifth player that acts as a central routing switch, or "gateway", for the exchange of highly-secured electronic payment information between final users (consumers and retailers) and their banks (issuers and aquirers). In countries such as the Netherlands, Belgium, France, Norway, and Switzerland a nation-wide debit card network exists with only one central routing switch. Such a central switch is often a separate firm jointly owned by the commercial banks.

In the Netherlands, the central routing switch, called Interpay, also plays an important role in signing up retailers to accept debit cards. Due to scale economies, Dutch commercial banks have opted for a nation-wide debit card network with only one delegated acquirer. All aquiring services are handled by the central routing switch for which it receives a per-transaction merchant discount from the retailer. Interestingly, and in contrast with most other countries, the Dutch debit card system does not implement any interchange fee. In the model described below we assume that the central routing switch enjoys a "double-monopolistic" role, in the sense that it sets prices for both the consumer and the retailer. Figure 2 depicts a schematic representation of a debit card payment in the Dutch system and the corresponding flow of funds and fees.

\section{A. The Debit Card Model}

Our model of payment services is a five-player model and may be thought of as being a stylized representation of a debit card payment system, also applicable to the Dutch market for debit card payments. In our model, the network routing switch, that we dub "Switch", plays various roles in the payment network. First, it facilitates the exchange of (secured) payment information between consumers and retailers and their respective banks. Second, it enjoys a double-monopoly position, in the sense that it is able to set the fees for debit card transactions for both consumers and retailers. Third, it is jointly owned by the banks: banks are reimbursed 
Figure 2. The "Dutch" Debit Card Model: Delegated Acquiring

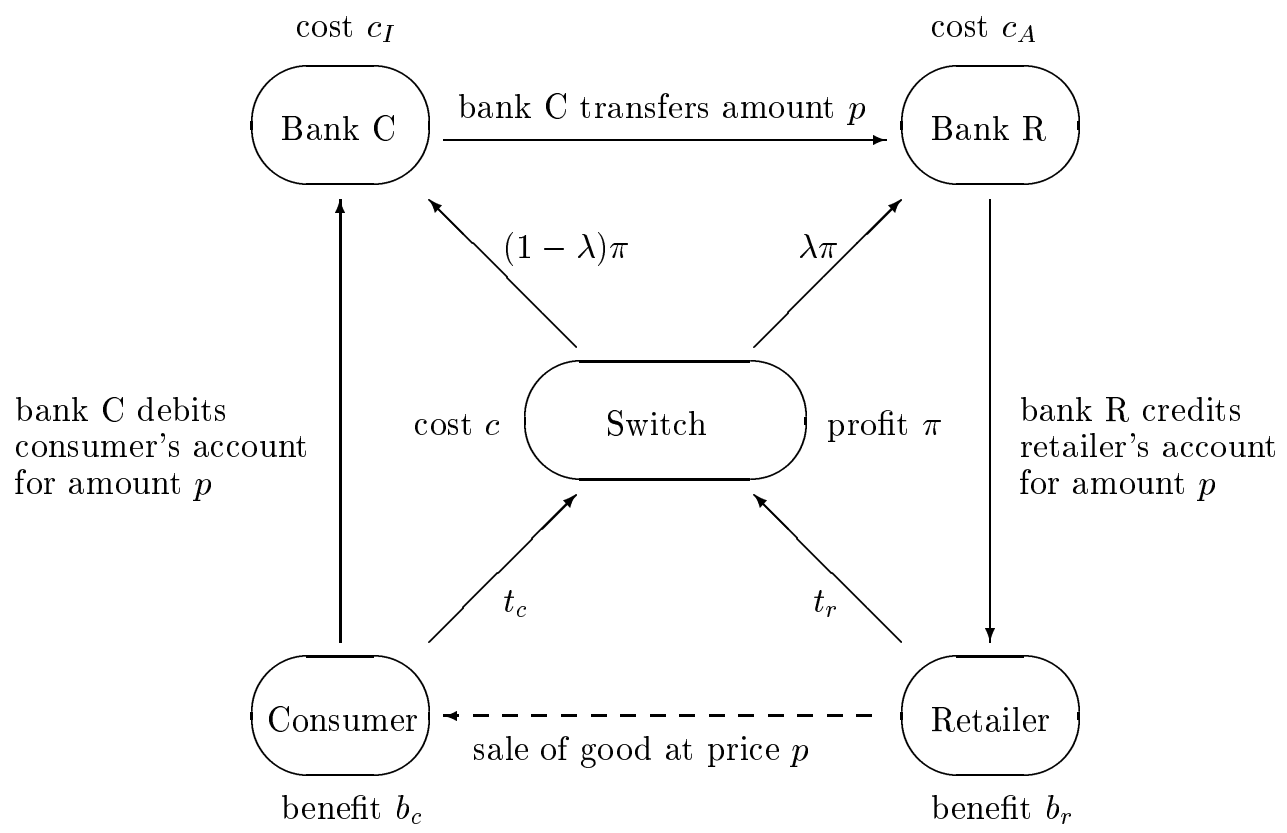

for their costs in processing the payment by the network switch via its profits.

When the consumer buys a good or service from the retailer at price $p>0$ using a debit card, the retailer's EFTPOS terminal contacts Switch. ${ }^{8}$ Switch routes all relevant consumer payment data to the consumer's bank C, and facilitates authorisation of the payment. Payment information is then routed to the retailer's bank $\mathrm{R}$ also. For these services, Switch charges both the retailer a transaction fee of $t_{r} \geq 0$ and the consumer a transaction fee $t_{c} \geq 0$. For simplicity, we abstract from any fixed periodic fees for end-users and interchange fees between debiting and crediting banks. ${ }^{9}$ Switch incurs marginal costs in performing its tasks, which are set at $c \geq 0$ per debit card transaction. We simply assume an additive cost structure $c=c_{c}+c_{r}$, where $c_{i}, i=c, r$, denotes the incurred costs on the consumer and retailer side of the downstream market when executing a single debit card transaction.

After payment authorisation by bank $\mathrm{C}$, it debits the consumer's account for the amount $p$ and transfers this money to bank $\mathrm{R}$. In doing so bank $\mathrm{C}$ incurs costs $c_{I}>0$. Bank $\mathrm{R}$ credits the retailer's account for the amount $p$ and incurs costs $c_{A}>0$. In collecting fees $t_{c}+t_{r}$ and incurring costs $c$, Switch runs a (net) profit $\pi\left(t_{c}, t_{r}, c\right)$. This profit is distributed proportionally

\footnotetext{
${ }^{8}$ EFTPOS (Electronic Funds Transfer at Point Of Sale) payment terminals are necessary to process debit card payments at retail locations.
}

${ }^{9}$ As already pointed out, in the current Dutch debit card system, no interchange fees are imposed. 
among its shareholders, which are precisely the payor's and payee's banks. We label the fraction of ownership of the consumer's bank by $1-\lambda, \lambda \in(0,1)$, while the retailer's bank is entitled to a fraction $\lambda$ of Switch's profits. Thus per transaction, Switch transfers an amount $\lambda\left(t_{c}+t_{r}-c\right)$ to bank $\mathrm{R}$ and an amount $(1-\lambda)\left(t_{c}+t_{r}-c\right)$ to bank $\mathrm{C}$. Let us denote total price of a single debit card transaction by $t$ so that $t=t_{c}+t_{r}$, and total cost by $c_{T}$ so that $c_{T}=c+c_{I}+c_{A}$.

A consumer chooses to use a debit card for a payment when he gets positive benefits from using the card relative to other payment instruments, say cash. Consumers are heterogeneous in the benefits $b_{c} \in\left[\underline{b}_{c}, \bar{b}_{c}\right], \bar{b}_{c} \leq \infty$, they receive from debit card usage. They choose to use the card whenever these benefits are larger than the associated costs $t_{c}$. The probability density function of these benefits is labelled $h_{c}(\cdot)$ with cumulative density $H_{c}(\cdot)$. All consumers with benefits larger than the incurred fee $t_{c}$ will use the card, i.e. the fraction of consumers who use the card will be

$$
q_{c}=D_{c}\left(t_{c}\right)=\operatorname{Pr}\left(b_{c} \geq t_{c}\right)=1-H_{c}\left(t_{c}\right) .
$$

Similarly, let us define the benefits from card usage relative to cash for the retailer as $b_{r} \in\left[\underline{b}_{r}, \bar{b}_{r}\right], \bar{b}_{r} \leq \infty$, with probability density function $h_{r}(\cdot)$ and cumulative density $H_{r}(\cdot)$. As before, the fraction of retailers who facilitate card usage depends on incurred fees $t_{r}$ and is equal to

$$
q_{r}=D_{r}\left(t_{r}\right)=\operatorname{Pr}\left(b_{r} \geq t_{r}\right)=1-H_{r}\left(t_{r}\right) .
$$

The total expected fraction of payments with the debitcard then equals the probability that a consumers who prefers the card meets a retailer who accepts it, which amounts to

$$
q=D\left(t_{c}, t_{r}\right)=D_{c}\left(t_{c}\right) D_{r}\left(t_{r}\right)
$$

We assume that Switch operates in a price region such that the price elasticities of (quasi)demand exceed 1 in both markets. That is, $\epsilon_{i}(t)=-\frac{\partial D_{i}}{\partial t} \frac{t}{D_{i}}>1, i=c, r$, for every feasible fee $t \geq 0$.

Finally, we exogenously fix the total number of payments at $N$.

\section{B. Double Monopoly, Two-Sidedness, and Pricing Strategy}

A basic feature of the market for electronic payment services is its two-sidedness. ${ }^{10}$ Cardholders attach value to their debit card only to the extent that these are accepted by the

\footnotetext{
${ }^{10}$ For a first rigorous analysis of two-sided markets, see Rochet and Tirole (2001).
} 
retailers that they visit for shopping; in turn, affiliated retailers benefit from a widespread diffusion of debit card among consumers. This network externality is usually called the "chicken-and-egg" problem of payment instruments, and is characterized by the presence of two distinct sides of end-users (here, consumers and retailers) whose ultimate benefits arise from interaction through the payment network. By setting its transaction fees, the network switch who monopolizes the use of the electronic payment network must make sure that both sides of the market "get on board".

In our model both sides of the downstream market for debit card payments are serviced by Switch. Switch is thus able to set transaction fees for both consumers and retailers and hence enjoys a double monopoly. This double monopoly situation has strong implications for the pricing of payment services, which depends on price elasticities of demand of consumers and retailers. This is seen as follows. Recall that Switch's profits are given by

$$
\pi\left(t_{c}, t_{r}, c\right)=\left(t_{c}+t_{r}-c\right) D\left(t_{c}, t_{r}\right)
$$

It sets optimal fees by maximizing its profit function, conditional on retailer and consumer participation. That is ${ }^{11}$

$$
\begin{aligned}
\max _{t_{c}, t_{r}} & \pi\left(t_{c}, t_{r}, c\right) \\
\text { subject to } & t_{c} \geq \underline{b}_{c}, t_{r} \geq \underline{b}_{r} .
\end{aligned}
$$

The Lagrangian becomes

$$
L=\pi\left(t_{c}, t_{r}, c\right)-\lambda_{c}\left(t_{c}-\underline{b}_{c}\right)-\lambda_{r}\left(t_{r}-\underline{b}_{r}\right)
$$

Algebraic manipulations lead to two types of results, depending on the choice of the distribution function $H(\cdot)$ of benefits across end-users of debit card services. In particular, under log-concavity of the the induced demand function $D(\cdot)=1-H(\cdot)$, the global maximum is determined by the interior solution. Otherwise, a corner solution typically leads to maximum profits. First, let us denote the optimal fees that yield the global maximum by $\left(t_{c}^{o}, t_{r}^{o}\right)$, the interior solution by $\left(t_{c}^{i n t}, t_{r}^{i n t}\right)$, and the corner solutions by $\left(t_{c}^{c o}, t_{r}^{c o}\right)$. Second, total elasticity of demand is defined by the sum of the two market sides' elasticities, that is, $\epsilon\left(t_{c}, t_{r}\right)=\epsilon_{c}\left(t_{c}\right)+\epsilon_{r}\left(t_{r}\right)$. Consider the following theorem, which is due to Rochet and Tirole $(2001)$.

\footnotetext{
${ }^{11}$ Since $D_{i}\left(t_{i}\right)=1$ for all $t_{i} \leq \underline{b}_{i}, i=c, r$, Switch will never charge below the minimum benefit levels $\underline{b}_{i}, i=c, r$.
} 
Theorem 1. (Interior solution)

i) The interior solution $\left(t_{c}^{i n t}, t_{r}^{i n t}\right)$ is given by

$$
t_{c}^{i n t}=\frac{c \epsilon_{c}^{i n t}}{\epsilon^{i n t}-1}, \quad t_{r}^{i n t}=\frac{c \epsilon_{r}^{i n t}}{\epsilon^{i n t}-1},
$$

where $\epsilon_{i}^{\text {int }}=\epsilon_{i}\left(t_{i}^{i n t}\right), i=c, r$, and $\epsilon^{\text {int }}=\epsilon_{c}^{\text {int }}+\epsilon_{r}^{i n t}$.

ii) The corresponding price structure is characterized by

$$
\frac{t_{c}^{i n t}}{t_{r}^{i n t}}=\frac{\epsilon_{c}^{i n t}}{\epsilon_{r}^{i n t}} .
$$

iii) The total fee $t^{i n t}=t_{c}^{i n t}+t_{r}^{i n t}$ is determined by the 'inverse elasticity rule' for total elasticity $\epsilon^{i n t}=\epsilon_{c}^{i n t}+\epsilon_{r}^{i n t}$. That is,

$$
\frac{t^{i n t}-c}{t^{i n t}}=\frac{1}{\epsilon^{i n t}}
$$

iv) Under log-concavity of $D(\cdot)$, the interior solution yields the global maximum. That is, $\left(t_{c}^{o}, t_{r}^{o}\right)=\left(t_{c}^{i n t}, t_{r}^{i n t}\right)$.

Proof

The proof of this theorem is found by simply solving the first-order conditions. These conditions generalize the equality between marginal revenue and marginal cost and yield

$$
\frac{t_{i}-c_{i}}{t_{i}}=\frac{1}{\epsilon_{i}}-\frac{t_{j}-c_{j}}{t_{i}}, \quad i, j=c, r, i \neq j .
$$

Solving for the interior prices $t_{c}^{i n t}$ and $t_{r}^{i n t}$ yields the expressions (8), (9), and (10) in Theorem 1. Log-concavity of the distribution functions ensures that the second-order conditions are satisfied, so that the interior solution represents a global maximum.

Theorem 1 indeed shows that under log-concavity optimal pricing in a two-sided market is still governed by the well known monopolistic Lerner pricing rule. But note that this rule only holds for the market as a whole: the mark-up (or Lerner index) depends on total price and total elasticity. So, if the market as a whole gets less elastic, the total price will rise. The distribution of the optimal total fee over the two markets is determined by the relative magnitude of the individual market side elasticities, as seen from (9). In our opinion, this gives rise to a counterintuitive result. Consider the next corollary that is directly derived from Theorem 1.

Corollary 2. Under log-concavity, the market side with the highest price elasticity of demand is charged the highest fee. That is, if $\epsilon_{i}^{i n t}>\epsilon_{j}^{i n t}$ then $t_{i}^{i n t}>t_{j}^{i n t}, i, j=c, r, i \neq j$.

Compare this result to the theoretic case of a multiproduct monopolist with complementary products, where one would instead find a lower price for the more elastic market. ${ }^{12}$ Empirical

\footnotetext{
${ }^{12}$ See Tirole (1989) for optimal pricing strategies in multiproduct markets.
} 
evidence also points in this direction. Currently in the Netherlands, consumers pay no transaction fee for using their debit cards, only retailers pay such a fee. In the context of Theorem 1 this would imply that consumers would be either totally inelastic, $\epsilon_{c}^{i n t}=0$ in absolute terms, or much less elastic relative to retailers, since $t_{c}^{i n t} \rightarrow 0$ as $\epsilon_{r}^{i n t} \rightarrow \infty$. However, recent empirical studies have shown that consumers are quite sensitive to price changes of payment services, see Humphrey, Kim, and Vale (2001). Hence, this seems to indicate that log-concavity of the demand function is not an appropriate assumption, implying that possibly $\left(t_{c}^{o}, t_{r}^{o}\right) \neq\left(t_{c}^{i n t}, t_{r}^{i n t}\right)$. As seen below, some corner solutions are much more in line with intuition and provide an explanation for the Dutch practice of setting prices of debit card payments.

A corner solution with Lagrange multiplier $\lambda_{i} \neq 0$ is characterized by player $i$ being tied down to its minimum benefit level $\underline{b}_{i}$ and player $j$ being charged a (generalized) monopoly price $t_{j}^{G M}$. That is, a corner solution $\left(t_{i}^{c o}, t_{j}^{c o}\right)$ is given by

i) $t_{i}^{c o}=\underline{b}_{i}$, and

ii) $t_{j}^{c o}=t_{j}^{G M}$, with $t_{j}^{G M}=\arg \max _{t_{j}} \pi\left(\underline{b}_{i}, t_{j}, c\right), \quad i, j=c, r, i \neq j$.

Note first that in the low-price market, demand is at its maximum, i.e. $D_{i}\left(t_{i}^{c o}\right)=1$. Second, $t_{j}^{c o}$ is not the ordinary monopoly price in market $j$, since the total downstream cost $c=c_{i}+c_{j}$ incurred in both markets is taken into account. The price can therefore even be higher than the "ordinary" one-sided monopoly price.

Depending on the choice of the underlying distribution for the benefits of a debit card transaction, the interior solution may be a (global) maximum or a saddlepoint. We will discuss two different benefit distributions to illustrate this point.

\section{Uniform distribution}

We impose the following probability density function

$$
f_{\underline{b}_{i}, \bar{b}_{i}}^{U}(x)=\frac{1}{\bar{b}_{i}-\underline{b}_{i}}, \quad x \in\left[\underline{b}_{i}, \bar{b}_{i}\right], \quad i=c, r,
$$

which yields a log-concave demand function, given by

$$
D_{i}^{U}(t)=\frac{\left(\bar{b}_{i}-t\right)}{\bar{b}_{i}-\underline{b}_{i}}, \quad t \in\left[\underline{b}_{i}, \bar{b}_{i}\right], \quad i=c, r .
$$

Log-concavity ensures that the interior solution represents the global maximum. The induced profit function is given by

$$
\pi^{U}\left(t_{c}, t_{r}, c\right)=\frac{\left(\bar{b}_{c}-t_{c}\right)\left(\bar{b}_{r}-t_{r}\right)\left(t_{c}+t_{r}-c\right)}{\left(\bar{b}_{c}-\underline{b}_{c}\right)\left(\bar{b}_{r}-\underline{b}_{r}\right)} .
$$

The elasticity is determined by

$$
\epsilon_{i}^{U}(t)=t /\left(\bar{b}_{i}-t\right)
$$


which is increasing in $t$ and decreasing in $\bar{b}_{i}$. Straightforward calculations show

$$
t_{c}^{U, o}=\frac{1}{3}\left(2 \bar{b}_{c}-\bar{b}_{r}+c\right), \quad t_{r}^{U, o}=\frac{1}{3}\left(2 \bar{b}_{r}-\bar{b}_{c}+c\right) .
$$

By substituting the optimal prices in the elasticities, we derive

$$
\epsilon_{c}^{U, o}=\epsilon_{c}^{U}\left(t_{c}^{U, o}\right)=\frac{3 \bar{b}_{c}}{\bar{b}_{c}+\bar{b}_{r}-c}-1, \quad \epsilon_{r}^{U, o}=\epsilon_{r}^{U}\left(t_{r}^{U, o}\right)=\frac{3 \bar{b}_{r}}{\bar{b}_{c}+\bar{b}_{r}-c}-1
$$

which is increasing in $\bar{b}_{i}, i=c, r$. It is easy to check that the consumer's optimal elasticity is larger than the retailer's optimal elasticity if and only if $\bar{b}_{c}>\bar{b}_{r}$. However, it also holds that $t_{c}^{U, o}>t_{r}^{U, o}$ if and only if $\bar{b}_{c}>\bar{b}_{r}$. So, here we observe the counterintuitive result that higher maximum benefit levels induce higher elasticities in the optimum and causes higher prices.

Although a higher maximum benefit level decreases the elasticity in first instance, as seen from (15), optimal quantities and prices also adjust. This in turn influences the elasticity. The net result is higher elasticities and higher tariffs. As a result, in line with Corollary 2, the most elastic side of the market pays the highest fee.

For the market as a whole, however, this result is reversed. We calculate

$$
t^{U, o}=t_{c}^{U, o}+t_{r}^{U, o}=\frac{1}{3}\left(\bar{b}_{c}+\bar{b}_{r}+2 c\right), \quad \text { and } \quad \epsilon^{U, o}=\epsilon_{c}^{U, o}+\epsilon_{r}^{U, o}=\frac{\bar{b}_{c}+\bar{b}_{r}+2 c}{\bar{b}_{c}+\bar{b}_{r}-c},
$$

with $\partial t^{U, o} / \partial \bar{b}_{i}>0$ and $\partial \epsilon^{U, o} / \partial \bar{b}_{i}<0, i=c, r$. Indeed, we get $\left(t^{U, o}-c\right) / t^{U, o}=1 / \epsilon^{U, o}$. Hence, on aggregate, higher maximum benefit levels translate to lower total optimal elasticities, which cause higher total optimal prices.

Net profits per transaction $\pi_{q}\left(t, c_{T}\right)$ are given by total price minus total costs, that is,

$$
\pi_{q}\left(t^{U, o}, c_{T}\right)=t_{c}^{U, o}+t_{r}^{U, o}-c_{T}=\frac{1}{3}\left(\bar{b}_{c}+\bar{b}_{r}-\left(c_{T}+2\left(c_{I}+c_{A}\right)\right)\right) .
$$

From this we conclude that there is a positive margin on a single debit card transaction whenever maximum benefit levels are high enough, i.e.,

$$
\pi_{q}\left(t^{U, o}, c_{T}\right) \geq 0 \quad \text { if and only if } \quad \bar{b}_{c}+\bar{b}_{r} \geq c_{T}+2\left(c_{I}+c_{A}\right)
$$

An example may clarify these findings. 
Table 1. Uniform Distribution: Prices and Profits

\begin{tabular}{lllll}
\hline & & \multicolumn{3}{c}{ Interior Solution } \\
\cline { 3 - 4 } & & Consumer & Retailer & Total \\
\hline & & & & \\
Price: & $t_{i}$ & 0.15 & 0.19 & 0.33 \\
Elasticity: & $\epsilon^{U}\left(t_{i}\right)$ & 2.75 & 3.50 & 6.25 \\
Demand (in \%): & $D_{i}^{U}\left(t_{i}\right)$ & 53.3 & 35.6 & 19.0 \\
& & & & \\
Profit: & & & & 10.11 \\
Switch & $\pi^{U}\left(t_{c}, t_{r}, c\right)$ & & & 13.53 \\
network & $\pi^{U}\left(t_{c}, t_{r}, c_{T}\right)$ & & & \\
per transaction $\left(\times 10^{-3}\right)$ & $\pi_{q}\left(t_{c}, t_{r}, c_{T}\right)$ & & & 12.6 \\
& & & &
\end{tabular}

Parameters: $c=0.28\left(c_{c}=c_{r}=0.14\right), c_{T}=0.32\left(c_{A}=c_{I}=0.02\right), \underline{b}_{c}=0.10, \bar{b}_{c}=0.20, \underline{b}_{r}=0.09$, $\bar{b}_{r}=0.24, N=1000$.

Example I: Uniform Distribution

Put the following parameter values: $c=0.28\left(c_{c}=c_{r}=0.14\right), c_{T}=0.32\left(c_{A}=c_{I}=0.02\right)$, $\underline{b}_{c}=0.10, \bar{b}_{c}=0.20, \underline{b}_{r}=0.09, \bar{b}_{r}=0.24$. Under these parameters, the expected consumer's benefit level is $\mathbb{E}\left(b_{c}\right)=0.15$, and the expected retailer's benefit level is $\mathbb{E}\left(b_{r}\right)=0.165$. We normalize the total number of transactions at one thousand, i.e. $N=1000$. Table 1 gives the results for the interior solution.

Indeed, we observe that higher optimal prices correspond to higher optimal elasticities. On aggregate, the Lerner rule holds: $\left(t^{U, o}-c\right) / t^{U, o}=0.16=1 / \epsilon^{U, o}$. Under these parameters, around one fifth of all transactions will be made using debit card. Both Switch and the total debit card network make positive profits. Note that positive profit margins are realised, since the condition of (20) is satisfied, or $\bar{b}_{c}+\bar{b}_{r}=0.44 \geq c_{T}+2\left(c_{I}+c_{A}\right)=0.40$. Further, also notice that both markets earn positive profits, i.e. $t_{c}^{U, o}=0.15 \geq c_{c}=0.14$, and $t_{c}^{U, o}=0.19 \geq c_{r}=0.14$. Figure 3 demonstrates that the interior solution indeed induces the global maximum.

\section{Constant Elasticity Distribution}

We impose the following probability density function

$$
f_{\underline{b}_{i}, \epsilon_{i}}^{C}(x)=\underline{b}_{i}^{\epsilon_{i}} \epsilon_{i} x^{-\epsilon_{i}-1}, \quad x \in\left[\underline{b}_{i}, \infty\right], \quad \underline{b}_{i}>0, \quad \epsilon_{i}>1, \quad i=c, r .
$$


This density function yields a demand $D_{i}^{C}(t)$ that is not log-concave

$$
D_{i}^{C}(t)=\underline{b}_{i}^{\epsilon_{i}} t^{-\epsilon_{i}}
$$

and features a constant elasticity $\epsilon_{i}$. The induced profit function is given by

$$
\pi^{C}\left(t_{c}, t_{r}, c\right)=\underline{b}_{c}^{\epsilon_{c}} \underline{b}_{r}^{\epsilon_{r}} t_{c}^{-\epsilon_{c}} t_{r}^{-\epsilon_{r}}\left(t_{c}+t_{r}-c\right)
$$

Solving the first-order conditions yields

$$
t_{c}^{C, \text { int }}=\frac{c \epsilon_{c}}{\epsilon_{c}+\epsilon_{r}-1}, \quad t_{r}^{C, \text { int }}=\frac{c \epsilon_{r}}{\epsilon_{c}+\epsilon_{r}-1} .
$$

However, the second-order conditions show that this interior solution is a saddlepoint. Instead, a corner solution determines the global maximum. Under constant elasticity of demand, the two corner solutions are given by

$$
\left(\underline{b}_{c}, t_{r}^{G M}\right)=\left(\underline{b}_{c}, \frac{\left(c-\underline{b}_{c}\right) \epsilon_{r}}{\epsilon_{r}-1}\right), \text { and } \quad\left(t_{c}^{G M}, \underline{b}_{r}\right)=\left(\frac{\left(c-\underline{b}_{r}\right) \epsilon_{c}}{\epsilon_{c}-1}, \underline{b}_{r}\right)
$$

The next proposition states that optimal pricing induces the low-elastic side of the market being charged the highest price, whereas the high-elastic side is kept to its minimum benefit level. In the high-elastic, low-price market, participation is complete, so that demand for debit card services on this side of the market is at its maximum. Consider the following proposition.

Proposition 3. (Corner solution)

i) Assume a constant elasticity distribution as specified in (21). If $\underline{b}_{c}+\underline{b}_{r} \leq c$ then there exists $\bar{\epsilon} \geq \epsilon_{j}$, such that for $\epsilon_{i}>\bar{\epsilon}$ it holds that

$$
t_{i}^{C, o}=\underline{b}_{i} \text { and } t_{j}^{C, o}=t_{j}^{G M}=\frac{\left(c-\underline{b}_{i}\right) \epsilon_{j}}{\epsilon_{j}-1}, \quad i, j=c, r, i \neq j .
$$

ii) The most elastic side has complete participation. That is, if $\underline{b}_{c}+\underline{b}_{r} \leq c$ and $\epsilon_{i}>\bar{\epsilon} \geq \epsilon_{j}$, then $D_{i}^{C}\left(t_{i}^{C, o}\right)=1, i, j=c, r, i \neq j$.

Proof

i) First, one may verify that

$$
\pi^{C}\left(\underline{b}_{c}, t_{r}^{G M}, c_{T}\right)=\frac{\underline{b}_{r}^{\epsilon_{r}}\left(\frac{\epsilon_{r}\left(c-\underline{b}_{c}\right)}{\epsilon_{r}-1}\right)^{1-\epsilon_{r}}}{\epsilon_{r}} .
$$

and

$$
\pi^{C}\left(t_{c}^{G M}, \underline{b}_{r}, c_{T}\right)=\frac{\underline{b}_{c}^{\epsilon_{c}}\left(\frac{\epsilon_{c}\left(c-\underline{b}_{r}\right)}{\epsilon_{c}-1}\right)^{-\epsilon_{c}}}{\epsilon_{c}} .
$$


Figure 3. Profits under a Uniform Distribution: Global Maximum

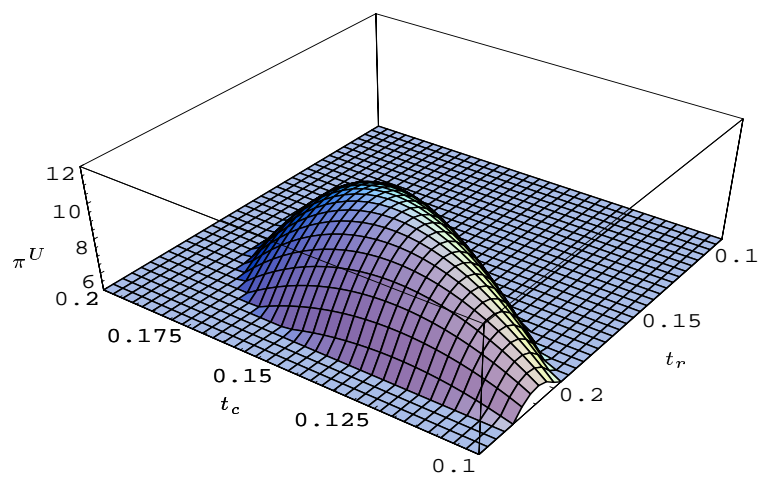

Note: The interior solution $(0.15,0.19)$ induces a global maximum (profits below 6.0 are surpressed).

These values exist and are positive for sufficiently small minimum benefit levels, i.e if $\underline{b}_{i} \leq c$, $i=c, r$. Second, observe that $\pi^{C}\left(\underline{b}_{i}, t_{j}^{G M}, c\right)$ is constant in $\epsilon_{i}$. In the limit, as $\epsilon_{c} \rightarrow \infty$ and holding $\epsilon_{r}$ constant, we compute $\pi_{c}^{C}=\lim _{\epsilon_{c} \rightarrow \infty} \pi^{C}\left(\underline{b}_{c}, t_{r}^{G M}, c_{T}\right)=\pi^{C}\left(\underline{b}_{c}, t_{r}^{G M}, c_{T}\right)>0$, and $\pi_{r}^{C}=\lim _{\epsilon_{c} \rightarrow \infty} \pi^{C}\left(t_{c}^{G M}, \underline{b}_{r}, c_{T}\right)=0$. Third, we derive

$$
\frac{\partial \pi^{C}\left(t_{i}^{G M}, \underline{b}_{j}, c\right)}{\partial \epsilon_{i}}=-\frac{\left(c-\underline{b}_{j}\right)\left(\frac{\epsilon_{i}\left(c-\underline{b}_{j}\right)}{\underline{b}_{i}\left(\epsilon_{i}-1\right)}\right)^{-\epsilon_{i}} \log \left(\frac{\epsilon_{i}\left(c-\underline{b}_{j}\right)}{\underline{b}_{i}\left(\epsilon_{i}-1\right)}\right)}{\epsilon_{i}-1}<0
$$

if and only if $\log \left(\frac{\epsilon_{i}\left(c-\underline{b}_{j}\right)}{\underline{b}_{i}\left(\epsilon_{i}-1\right)}\right) \geq 0$. Hence, $\pi^{C}\left(t_{i}^{G M}, \underline{b}_{j}, c\right)$ is decreasing for every $\epsilon_{i}>1$ if and only if $\underline{b}_{i}+\underline{b}_{j} \leq c$. Since $\pi^{C}\left(t_{i}^{G M}, \underline{b}_{j}, c\right)$ is decreasing in $\epsilon_{i}$ and $\pi^{C}\left(\underline{b}_{i}, t_{j}^{G M}, c\right)$ is constant, and $\pi_{r}^{C}<\pi_{c}^{C}$, this implies that there exists an $\bar{\epsilon} \geq \epsilon_{j}$ such that for $\epsilon_{i}>\bar{\epsilon}$ it holds that $\pi^{C}\left(\underline{b}_{i}, t_{j}^{G M}, c\right)>\pi^{C}\left(t_{i}^{G M}, \underline{b}_{j}, c\right)$. Hence, $\left(t_{i}^{C, o}, t_{j}^{C, o}\right)=\left(\underline{b}_{i}, t_{j}^{G M}\right) .{ }^{13}$ Existence of derivative (29) requires $\underline{b}_{j} \leq c$ which is automatically guaranteed if $\underline{b}_{i}+\underline{b}_{j} \leq c$.

ii) If $\underline{b}_{i}+\underline{b}_{j} \leq c$ then, from $i$ ), we know that $t_{i}^{C, o}=\underline{b}_{i}$ for $\epsilon_{i}>\bar{\epsilon} \geq \epsilon_{j}$. By definition, $D_{i}^{C}\left(\underline{b}_{i}\right)=1$, that is, complete participation.

Proposition 3 has interesting implications. Recent empirical analysis has shown that consumers are quite sensitive to price changes of payment services, see e.g. Humphrey, Kim, and Vale (2001). Retailers, instead, often complain that due to competitive pressures they are "forced" to facilitate debit card services. Retailers cannot afford to sell "no" to their customers. At the same time, they do not see many payment alternatives. In this sense, retailers are much less

\footnotetext{
${ }^{13}$ Note that, due to symmetry, if $\underline{b}_{i}=\underline{b}_{j}$ then $\pi^{C}\left(\underline{b}_{i}, t_{j}^{G M}, c\right)=\pi^{C}\left(t_{i}^{G M}, \underline{b}_{j}, c\right)$ for $\epsilon_{i}=\epsilon_{j}$. Further, one can show that $\bar{\epsilon}>\epsilon_{j}$ for $\underline{b}_{i}>\underline{b}_{j}$; otherwise, for $\underline{b}_{i} \leq \underline{b}_{j}$ one may choose $\bar{\epsilon}=\epsilon_{j}$.
} 
price elastic in their demand for debit card services. If we therefore assume that consumer demand is sufficiently more price elastic than retailer demand, we then derive the following corollary.

\section{Corollary 4.}

If consumer's price elasticity of demand is sufficiently large, then, under a constant elasticity distribution, consumers pay the lowest admissible price and retailers are charged a high generalized monopoly price. That is, if $\underline{b}_{c}+\underline{b}_{r} \leq c$ then there exists $\bar{\epsilon}$ such that for $\epsilon_{c}>\bar{\epsilon} \geq \epsilon_{r}$, we have that

$$
t_{c}^{C, o}=\underline{b}_{c}, \quad t_{r}^{C, o}=\frac{\left(c-\underline{b}_{c}\right) \epsilon_{r}}{\epsilon_{r}-1} .
$$

Consumer participation is complete, i.e. $D_{c}\left(t_{c}^{C, o}\right)=1$.

When the conditions of the corollary hold, the interesting phenomenon arises that the consumer side of the market is used to generate an increase in demand for debit card payments, for which the retailer pays. Effectively, consumers are subsidized by retailers so as to boost the demand for debit cards. This theoretical result exactly reflects the current practice in the Netherlands that consumers pay no transaction fee for using their debit cards. Only the retailers pay such a fee, which could theoretically even be higher than the "ordinary" one-sided monopoly price. More precisely, the one-sided monopoly price for retailers equals

$$
t_{r}^{M}=\arg \max _{t_{r}}\left(t_{r}-c_{r}\right) D_{r}\left(t_{r}\right)=\frac{c_{r} \epsilon_{r}}{\epsilon_{r}-1} .
$$

We state the following proposition without proof.

Proposition 5. Under constant elasticity of demand, the optimal retailer fee is higher than the one-sided monopoly price if the consumer's minimum benefit level is sufficiently small. That is, $t_{r}^{C, o} \geq t_{r}^{M}$ if and only if $\underline{b}_{c} \leq c_{c}$.

For sufficiently large consumer's elasticity of demand, net profits per transaction amount to

$$
\pi_{q}\left(t^{C, o}, c_{T}\right)=t_{c}^{C, o}+t_{r}^{C, o}-c_{T}=\frac{\left(c-\underline{b}_{c}\right) \epsilon_{r}}{\epsilon_{r}-1}-\left(c_{T}-\underline{b}_{c}\right) .
$$

Hence, positive profit margins are realized for sufficiently small consumer minimum benefit levels, i.e.

$$
\pi_{q}\left(t^{C, o}, c_{T}\right) \geq 0 \text { if and only if } \quad \underline{b}_{c} \leq c-\left(\epsilon_{r}-1\right)\left(c_{I}+c_{A}\right) .
$$

Lower consumer minimum benefit levels dampen the consumer fee, but increase the retailer fee. The latter effect dominates, so that profits per transaction increase when consumer minimum benefit levels decrease. That is, $\partial \pi_{q}\left(t^{C, o}, c_{T}\right) / \partial \underline{b}_{c}<0$. 
Table 2. Constant Elasticity Distribution: Prices and Profits

\begin{tabular}{|c|c|c|c|c|}
\hline & & \multirow{2}{*}{$\begin{array}{l}\text { Interior Solution } \\
\left(t_{c}^{C, \text { int }}, t_{r}^{C, \text { int }}\right)\end{array}$} & \multicolumn{2}{|c|}{ Corner Solutions } \\
\hline & & & $\begin{array}{l}\text { Consumer } \\
t_{c}^{C, c o}=\underline{b}_{c}\end{array}$ & $\begin{array}{c}\text { Retailer } \\
t_{r}^{C, c o}=\underline{b}_{r}\end{array}$ \\
\hline \multicolumn{5}{|l|}{ Price: } \\
\hline consumer fee & $t_{c}$ & 0.20 & 0.10 & 0.29 \\
\hline retailer fee & $t_{r}$ & 0.15 & 0.33 & 0.09 \\
\hline total fee & $t$ & 0.35 & 0.43 & 0.38 \\
\hline \multicolumn{5}{|l|}{ Demand (in \%): } \\
\hline consumer demand & $D_{c}^{C}\left(t_{c}, t_{r}\right)$ & 12.5 & 100.0 & 4.3 \\
\hline retailer demand & $D_{r}^{C}\left(t_{c}, t_{r}\right)$ & 24.1 & 5.7 & 100.0 \\
\hline total demand & $D^{C}\left(t_{c}, t_{r}\right)$ & 4.3 & 5.7 & 4.3 \\
\hline \multicolumn{5}{|l|}{ Profit: } \\
\hline Switch & $\pi^{C}\left(t_{c}, t_{r}, c\right)$ & 2.8 & 8.6 & 4.1 \\
\hline network & $\pi^{C}\left(t_{c}, t_{r}, c_{T}\right)$ & 1.1 & 6.3 & 2.4 \\
\hline per transaction $\left(\times 10^{-3}\right)$ & $\pi_{q}\left(t_{c}, t_{r}, c_{T}\right)$ & 26.7 & 110.0 & 55.0 \\
\hline Welfare: & $W^{C}\left(t_{c}, t_{r}, c_{T}\right)$ & 10.6 & 25.0 & 11.8 \\
\hline
\end{tabular}

Parameters: $\epsilon_{c}=3, \epsilon_{r}=2.2, \underline{b}_{c}=0.10, \underline{b}_{r}=0.09, c=0.28\left(c_{c}=c_{r}=0.14\right), c_{T}=0.32\left(c_{A}=c_{I}=0.02\right)$, $N=1000$; the number in italics indicates maximum profits.

The following example illustrates our findings.

\section{Example II: Constant Elasticity Distribution}

Put the following parameter values: $c=0.28\left(c_{c}=c_{r}=0.14\right), c_{T}=0.32\left(c_{A}=c_{I}=0.02\right)$, $\underline{b}_{c}=0.1, \underline{b}_{r}=0.09, \epsilon_{c}=3, \epsilon_{r}=2.2$, and $N=1000$. Under these parameters, the expected consumer's benefit level is $\mathbb{E}\left(b_{c}\right)=0.15$, and the expected retailer's benefit level is $\mathbb{E}\left(b_{r}\right)=0.165$. These expected values equal the expected benefit levels for the uniform distribution of example I. Table 2 gives the results for the different solutions.

The table indeed shows that the interior solution does not yield maximum profits for Switch. The interior solution $(0.20,0.15)$ is a saddlepoint as clearly depicted in the left panel of Figure 4. In line with Corollary 4 , with $\underline{b}_{c}+\underline{b}_{r}=0.19<c_{T}=0.32$ and $\epsilon_{c}=3>\epsilon_{r}=2.2$ sufficiently large, we observe that the "consumer" corner solution leads to maximum profits. Also, total demand is higher in the "consumer" corner solution compared to the interior solution. Complete consumer participation boosts total demand, which at the same time allows a higher price to be extracted from the relatively inelastic retailers. As a result, around $6 \%$ of all transaction payments are executed by debit card. Following (33), positive profit margins are realised, since $\underline{b}_{c}=0.10 \leq c-\left(\epsilon_{r}-1\right)\left(c_{I}+c_{A}\right)=0.23$. But note, that on the consumer side 
Figure 4. Profits under a Constant Elasticity Distribution
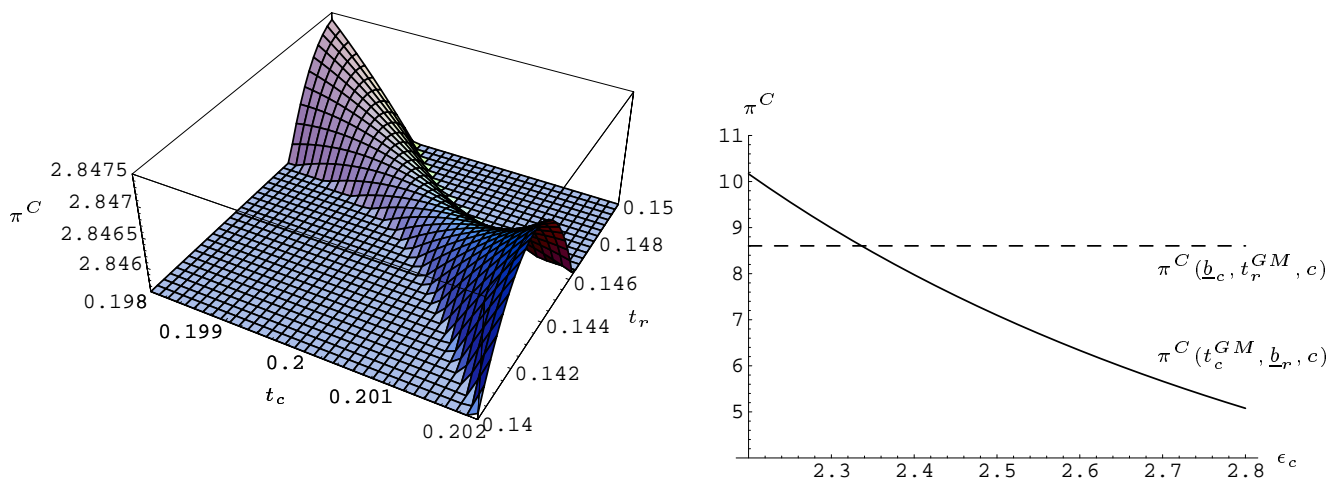

Note: The left panel shows that the interior solution $(0.20,0.15)$ is a saddlepoint (profits below 2.845 are surpressed); the right panel shows both 'corner' profit functions and verifies $\bar{\epsilon} \approx 2.34$.

operational losses are incurred since the charged consumer fee cannot make up for the costs, that is, $t_{c}^{C, o}=\underline{b}_{c}=0.10<c_{c}=0.14$. Hence, this side of the market is inevitably being cross-subsidized by the retailers.

The right panel of Figure 4 below shows both "corner" profit functions $\pi^{C}\left(\underline{b}_{c}, t_{r}^{G M}, c\right)$ and $\pi^{C}\left(t_{c}^{G M}, \underline{b}_{r}, c\right)$ as a function of $\epsilon_{c}$. We know that $\pi^{C}\left(\underline{b}_{c}, t_{r}^{G M}, c\right)$ is constant in $\epsilon_{c}$ whereas $\pi^{C}\left(t_{c}^{G M}, \underline{b}_{r}, c\right)$ is decreasing in $\epsilon_{c}$. It can be numerically verified that $\bar{\epsilon} \approx 2.34$. Hence, following Proposition 3, for every $\epsilon_{c}>2.34$, profits are maximized when consumers are tied down to their minimum benefit level. ${ }^{14}$ Retailers, instead, pay a high generalized monopoly price $t_{r}^{G M}=0.33$. Since $\underline{b}_{c}=0.10<c_{c}=0.14$, the "ordinary" monopoly price is smaller than the generalized monopoly price, that is, $t_{r}^{M}=0.26<t_{r}^{G M}=0.33$.

\section{Social Welfare}

In the model, the electronic payment network is run by the network switch who enjoys monopolistic power in setting prices for consumers and retailers. It is well known that a monopolist distorts the market by reducing supply of goods to raise prices, inducing a dead weight loss. In a payment network where network externalities play an important role, the underlying economics get more complicated.

In our model, total (expected) social welfare that is generated from debit card transactions is

\footnotetext{
${ }^{14}$ If the consumer's minimum benefit level would drop to below $\underline{b}_{r}=0.09$ than $\bar{\epsilon}$ would equal $\epsilon_{r}=2.2$.
} 
equal to consumer plus retailer (expected) benefits, conditional upon their participation in the debit card network, minus total costs. Formally, total social welfare is described by

$$
W\left(t_{c}, t_{r}, c_{T}\right)=\left(\beta_{c}\left(t_{c}\right)+\beta_{r}\left(t_{r}\right)-c_{T}\right) D\left(t_{c}, t_{r}\right),
$$

where $c_{T}=c_{A}+c_{I}+c$ represents the total cost of a single transaction over the payment network, and where $\beta_{c}\left(t_{c}\right)$ denotes the (conditional) expected benefit to a debit cardholder, defined by

$$
\beta_{c}\left(t_{c}\right)=\mathbb{E}\left(b_{c} \mid b_{c} \geq t_{c}\right)=\frac{\int_{t_{c}}^{\bar{b}_{c}} x h_{c}(x) d x}{1-H_{c}\left(t_{c}\right)},
$$

and, similarly for a retailer who accepts debit cards,

$$
\beta_{r}\left(t_{r}\right)=\mathbb{E}\left(b_{r} \mid b_{r} \geq t_{r}\right)=\frac{\int_{t_{r}}^{\bar{b}_{r}} x h_{r}(x) d x}{1-H_{r}\left(t_{r}\right)} .
$$

\section{A. Examining the Social Welfare Function}

We will examine the social welfare function (34) for the two probability distributions of consumer and retailer benefits applied in the previous section. Two questions of particular interest arise. First, under socially optimal prices, is the debit card network profitable or does it operate at a loss? Second, how do socially optimal prices compare to the prices set by the double-monopolist Switch?

\section{Uniform Distribution}

For uniform distributions of both consumer and retailer benefits, the social welfare function (34) becomes

$$
W^{U}\left(t_{c}, t_{r}, c_{T}\right)=\frac{\left(\bar{b}_{h}-t_{h}\right)\left(\bar{b}_{c}-t_{c}\right)\left(\bar{b}_{c}+\bar{b}_{c}-2 c_{T}+t_{c}+t_{r}\right)}{2\left(\bar{b}_{c}-\underline{b}_{c}\right)\left(\bar{b}_{r}-\underline{b}_{r}\right)} .
$$

Maximizing jointly over $t_{c}$ and $t_{r}$ yields the socially optimal fees

$$
t_{c}^{U, w}=\frac{1}{3}\left(\bar{b}_{c}-2 \bar{b}_{r}+2 c_{T}\right), \quad t_{r}^{U, w}=\frac{1}{3}\left(\bar{b}_{r}-2 \bar{b}_{c}+2 c_{T}\right) .
$$


Because of log-concavity, this solution is interior and represents a global maximum. It is straightforward to calculate that for sufficiently large maximum benefit levels, prices set by Switch are higher than socially optimal prices. More precise,

$$
t_{i}^{U, o} \geq t_{i}^{U, w} \quad \text { if and only if } \quad \bar{b}_{c}+\bar{b}_{r} \geq c_{T}+\left(c_{A}+c_{I}\right) .
$$

Combining (20) and (39), we deduce that in an economic environment where Switch makes positive profits, socially optimal prices will always be lower. Hence, by setting its optimal prices, Switch causes underprovision of debit card services.

In the social optimum, net profits per transaction amount to

$$
\pi_{q}\left(t^{U, w}, c_{T}\right)=t_{c}^{U, w}+t_{r}^{U, w}-c_{T}=\frac{1}{3}\left(c_{T}-\bar{b}_{c}-\bar{b}_{r}\right) .
$$

Thus, in the social optimum the banking sector will operate at a loss whenever maximum benefit levels are sufficiently large or, formally,

$$
\pi_{q}\left(t^{U, w}, c_{T}\right) \leq 0 \quad \text { if and only if } \quad \bar{b}_{c}+\bar{b}_{r} \geq c_{T} .
$$

Combining (20) and (41), we find that if Switch, making positive profits otherwise, is forced to implement socially optimal fees, this would result in a social loss. To overcome this profitability problem, (government) subsidies, cross-selling (implying cross subsidization), or imposing interchange fees may be needed to induce banks to participate in the electronic debit card payment network in order to attain the social optimum.

Example I (continued): Uniform distribution

As before, put the following parameter values: $c=0.28\left(c_{c}=c_{r}=0.14\right)$, $c_{T}=0.32\left(c_{A}=c_{I}=0.02\right), \underline{b}_{c}=0.10, \bar{b}_{c}=0.20, \underline{b}_{r}=0.09, \bar{b}_{r}=0.24, N=1000$. Under these parameters, the expected consumer's benefit level is $\mathbb{E}\left(b_{c}\right)=0.15$, and the expected retailer's benefit level is $\mathbb{E}\left(b_{r}\right)=0.165$. Table 3 gives the results for the social welfare maximizing solution, which is interior.

Comparing Table 3 to Table 1 we observe that socially optimal prices are lower than in the monopolistic case. This is confirmed by checking condition (39):

$\bar{b}_{c}+\bar{b}_{r}=0.44 \geq c_{T}+\left(c_{I}+c_{A}\right)=0.36$. Also, the socially optimal total demand for debit cards is more than two times higher than monopolistic demand: $44 \%$ vs. $19 \%$. However, by implementing the socially optimal prices $(0.12,0.16)$, Switch will make zero profits, since $t_{c}^{U, w}+t_{r}^{U, w}=0.28=c$. From condition (41) it follows that total profits per transaction will be negative, since $\bar{b}_{c}+\bar{b}_{r}=0.44 \geq c_{T}=0.32$. 
Table 3. Uniform Distribution: Social Welfare

\begin{tabular}{llccc}
\hline & & \multicolumn{3}{c}{ Interior Solution } \\
\cline { 3 - 4 } & & Consumer & Retailer & Total \\
\hline & & & & \\
Price: & $t_{i}$ & 0.12 & 0.16 & 0.28 \\
Elasticity: & $\epsilon^{U}\left(t_{i}\right)$ & 1.50 & 2.00 & 3.50 \\
Demand (in \%): & $D_{i}^{U}\left(t_{i}\right)$ & 80.0 & 53.3 & 43.7 \\
& & & \\
Profit: & $\pi^{U}\left(t_{c}, t_{r}, c\right)$ & & \\
$\quad$ Switch & $\pi^{U}\left(t_{c}, t_{r}, c_{T}\right)$ & & 0.0 \\
network & $\pi_{q}\left(t_{c}, t_{r}, c_{T}\right)$ & & -17.1 \\
per transaction $\left(\times 10^{-3}\right)$ & & -40.0 \\
Welfare: & $W^{U}\left(t_{c}, t_{r}, c_{T}\right)$ & & & \\
& & & & \\
\end{tabular}

Parameters: $c=0.28\left(c_{c}=c_{r}=0.14\right), c_{T}=0.32\left(c_{A}=c_{I}=0.02\right), \underline{b}_{c}=0.10, \bar{b}_{c}=0.20, \underline{b}_{r}=0.09$, $\bar{b}_{r}=0.24, N=1000$.

\section{Constant Elasticity Distribution}

By substititing the density function $f_{\underline{b}_{i}, \epsilon_{i}}^{C}(x)=\underline{b}_{i}^{\epsilon_{i}} \epsilon_{i} x^{-\epsilon_{i}-1}, x \in\left[\underline{b}_{i}, \infty\right], i=c, r$, in social welfare function (34), we get

$$
W^{C}\left(t_{c}, t_{r}, c_{T}\right)=\frac{\underline{b}_{c}^{\epsilon_{c}} \underline{b}_{r}^{\epsilon_{r}} t_{c}^{-\epsilon_{c}} t_{r}^{-\epsilon_{r}}\left(\epsilon_{c}\left(\epsilon_{r}-1\right) t_{c}+\epsilon_{r}\left(\epsilon_{c}-1\right) t_{r}-\left(\epsilon_{c}-1\right)\left(\epsilon_{r}-1\right) c_{T}\right)}{\left(\epsilon_{c}-1\right)\left(\epsilon_{r}-1\right)}
$$

$W^{C}\left(t_{c}, t_{r}, c_{T}\right)$ exhibits an interior saddle point solution. The global maximum is a corner solution where the side of the market with the higher elasticity of demand is charged the lowest admissible fee. Hence, this whole market is captured, while the other market is charged a higher fee. The next proposition states this result.

First, we define

$$
x_{c}=\arg \max _{x} W^{C}\left(x, \underline{b}_{r}, c_{T}\right)=c_{T}-\frac{\underline{b}_{r} \epsilon_{c}}{\epsilon_{c}-1},
$$

and

$$
x_{r}=\arg \max _{x} W^{C}\left(\underline{b}_{c}, x, c_{T}\right)=c_{T}-\frac{\underline{b}_{c} \epsilon_{r}}{\epsilon_{r}-1} .
$$

Consider the following proposition. 


\section{Proposition 6.}

In the case of a constant elasticity distribution, given a condition on minimum benefit levels, if consumer's price elasticity of demand is sufficiently large, then maximum social welfare is found at a corner solution in which consumers are kept to their minimum benefit level. That is, if $\underline{b}_{r} \leq \frac{1}{\epsilon_{r}}\left(\epsilon_{r}-1\right)\left(c_{T}-\underline{b}_{c}\right)$ then there exists $\bar{\epsilon} \geq \epsilon_{r}$ such that for $\epsilon_{c}>\bar{\epsilon}$, it holds that

$$
t_{c}^{C, w}=\underline{b}_{c}, \quad t_{r}^{C, w}=c_{T}-\frac{\underline{b}_{c} \epsilon_{r}}{\epsilon_{r}-1} .
$$

Consumer participation is complete, i.e. $D_{c}^{C}\left(t_{c}^{C, w}\right)=1$.

\section{Proof}

First, one may verify that ${ }^{15}$

$$
W^{C}\left(\underline{b}_{c}, x_{r}, c_{T}\right)=\frac{\underline{b}_{r}^{\epsilon_{r}}\left(c_{T}-\frac{\epsilon_{c} \underline{b}_{c}}{\epsilon_{c}-1}\right)^{-\epsilon_{r}}\left(\epsilon_{c}\left(c_{T}-\underline{b}_{c}\right)-c_{T}\right)}{\left(\epsilon_{r}-1\right)\left(\epsilon_{c}-1\right)}
$$

and

$$
W^{C}\left(x_{c}, \underline{b}_{r}, c_{T}\right)=\frac{\underline{b}_{c}^{\epsilon_{c}}\left(c_{T}-\frac{\epsilon_{r} \underline{b}_{r}}{\epsilon_{r}-1}\right)^{-\epsilon_{c}}\left(\epsilon_{r}\left(c_{T}-\underline{b}_{r}\right)-c_{T}\right)}{\left(\epsilon_{r}-1\right)\left(\epsilon_{c}-1\right)} .
$$

These values exist and are positive for sufficiently small minimum benefit levels, i.e if $\underline{b}_{i}<\frac{1}{\epsilon_{i}}\left(\epsilon_{i}-1\right) c_{T}, i=c, r$. In the limit, as $\epsilon_{c} \rightarrow \infty$, we compute

$$
W_{c}^{C}=\lim _{\epsilon_{c} \rightarrow \infty} W^{C}\left(\underline{b}_{c}, x_{r}, c_{T}\right)=\frac{\underline{b}_{r}^{\epsilon_{r}}\left(c_{T}-\underline{b}_{c}\right)^{1-\epsilon_{r}}}{\epsilon_{r}-1}>0
$$

and, if $\underline{b}_{r} \leq \frac{1}{\epsilon_{r}}\left(\epsilon_{r}-1\right)\left(c_{T}-\underline{b}_{c}\right)$ then

$$
W_{r}^{C}=\lim _{\epsilon_{c} \rightarrow \infty} W^{C}\left(\underline{b}_{c}, x_{r}, c_{T}\right)=0 .
$$

Third, it is straightforward to show that

$$
\frac{\partial W^{C}\left(\underline{b}_{c}, x_{r}, c_{T}\right)}{\partial \epsilon_{c}}=-\frac{\underline{b}_{r}^{\epsilon_{r}}\left(c_{T}-\frac{\epsilon_{c} \underline{b}_{c}}{\epsilon_{c}-1}\right)^{-\epsilon_{r}}}{\left(\epsilon_{c}-1\right)^{2}}<0
$$

and

$$
\begin{aligned}
\frac{\partial W^{C}\left(x_{c}, \underline{b}_{r}, c_{T}\right)}{\partial \epsilon_{c}}= & \frac{\underline{b}_{c}^{\epsilon_{c}}\left(c_{T}-\frac{\epsilon_{r} \underline{b}_{r}}{\epsilon_{r}-1}\right)^{-\epsilon_{c}}\left(\epsilon_{r}\left(c_{T}-\underline{b}_{r}\right)-c_{T}\right)}{\left(\epsilon_{r}-1\right)\left(\epsilon_{c}-1\right)^{2}} \times \\
& \frac{\left(\left(\epsilon_{r}-1\right) \log \left(\frac{\left(\epsilon_{r}-1\right) \underline{b}_{r}}{\epsilon_{r}\left(c_{T}-\underline{b}_{r}\right)-c_{T}}\right)-1\right)}{\left(\epsilon_{r}-1\right)\left(\epsilon_{c}-1\right)^{2}}<0
\end{aligned}
$$

\footnotetext{
${ }^{15}$ Note that due to symmetry $W^{C}\left(\underline{b}_{c}, x_{r}, c_{T}\right)=W^{C}\left(x_{c}, \underline{b}_{r}, c_{T}\right)$ for $\underline{b}_{c}=\underline{b}_{r}$ and $\epsilon_{c}=\epsilon_{r}$.
} 
for $\underline{b}_{r} \leq \frac{1}{\epsilon_{r}}\left(\epsilon_{r}-1\right)\left(c_{T}-\underline{b}_{c}\right)$. So, both value functions are monotonically decreasing, but converge to different limit points. Hence, because $W_{c}^{C}>W_{r}^{C}$, there exists an $\bar{\epsilon} \geq \epsilon_{r}$ such that for every $\epsilon_{c}>\bar{\epsilon}$ we have that $W^{C}\left(\underline{b}_{c}, x_{r}, c_{T}\right)>W^{C}\left(x_{c}, \underline{b}_{r}, c_{T}\right)$. Therefore, $t_{c}^{C, w}=\underline{b}_{c}$ and $t_{r}^{C, w}=x_{r}$ for sufficiently large $\epsilon_{c}$. Finally, by definition, $D_{c}^{C}\left(\underline{b}_{c}\right)=1$.

Net profits per transaction amount to

$$
\pi_{q}\left(t^{C, w}, c_{T}\right)=t_{c}^{C w}+t_{r}^{C w}-c_{T}=-\frac{\underline{b}_{c}}{\epsilon_{c}-1},
$$

which is smaller than zero, given $\epsilon_{c}>1$. That is,

$$
\pi_{q}\left(t^{C, w}, c_{T}\right) \leq 0 \text { if and only if } \epsilon_{c}>1
$$

Moreover, it can be shown that for sufficiently small consumer's minimum benefit value the socially optimal fee for the retailer is always lower than the double monopoly fee set by Switch. That is,

$$
t_{r}^{C, o} \geq t_{r}^{C, w} \quad \text { if and only if } \quad \underline{b}_{c} \leq c-\left(\epsilon_{r}-1\right)\left(c_{I}+c_{A}\right) \text {. }
$$

So, although retailers subsidizing consumer participation may be optimal from a social welfare point of view, the double-monopoly nature of the market levies suboptimally high tariffs on the retailers. This leads to underprovision of debit cards services. However, implementing the social optimum may involve a loss for the banking sector. This can be compensated by a goverment subsidy or cross subsidization from other sources of income. Imposing an interchange fee may also alleviate the problem.

Consider the continued example for results on the constant elasticity case.

Example II (continued):

As before, we put the following parameter values: $c=0.28\left(c_{c}=c_{r}=0.14\right)$, $c_{T}=0.32\left(c_{A}=c_{I}=0.02\right), \underline{b}_{c}=0.1, \underline{b}_{r}=0.09, \epsilon_{c}=3, \epsilon_{r}=2.2$, and $N=1000$. Under these parameters, the expected consumer's benefit level is $\mathbb{E}\left(b_{c}\right)=0.15$, and the expected retailer's benefit level is $\mathbb{E}\left(b_{r}\right)=0.165$. Table 4 summarizes the results for the diferent solutions.

First, from the table it immediately follows that the interior solution does not yield maximum social welfare. Maximum social welfare is achieved at the corner solution in which the consumer fee is set at the minimum benefit level. Figure 5 shows both "corner" welfare functions $W^{C}\left(\underline{b}_{c}, x_{r}, c_{T}\right)$ and $W^{C}\left(x_{c}, \underline{b}_{r}, c_{T}\right)$ as a function of $\epsilon_{c}$. The limit points are calculated as $W_{c}^{C}=\underline{b}_{r}^{\epsilon_{r}}\left(c_{T}-\underline{b}_{c}\right)^{1-\epsilon_{r}} /\left(\epsilon_{r}-1\right)=0.026$ and $W_{r}^{C}=0$. Following Proposition 6 , it can be 
Table 4. Constant Elasticity Distribution: Social Welfare

\begin{tabular}{llccc}
\hline & & Interior Solution & \multicolumn{2}{c}{ Corner Solutions } \\
& & $\left(t_{c}^{C, \text { int }}, t_{r}^{C, \text { int }}\right)$ & $\begin{array}{c}\text { Consumer } \\
t_{c}^{C, c o}=\underline{b}_{c}\end{array}$ & $\begin{array}{c}\text { Retailer } \\
t_{r}^{C, c o}=\underline{b}_{r}\end{array}$ \\
\hline Price: & & & & \\
$\quad$ consumer fee & $t_{c}$ & 0.15 & 0.10 & 0.16 \\
$\quad$ retailer fee & $t_{r}$ & 0.09 & 0.17 & 0.09 \\
$\quad$ total fee & $t$ & 0.24 & 0.27 & 0.25 \\
& & & & \\
Demand (in \%): & & 28.3 & 100.0 & 26.9 \\
$\quad$ consumer demand & $D_{c}^{C}\left(t_{c}, t_{r}\right)$ & 96.6 & 24.7 & 100.0 \\
retailer demand & $D_{r}^{C}\left(t_{c}, t_{r}\right)$ & 27.3 & 24.7 & 26.9 \\
total demand & $D^{C}\left(t_{c}, t_{r}\right)$ & & & \\
& & -9.9 & -2.5 & -9.4 \\
Profit: & $\pi^{C}\left(t_{c}, t_{r}, c\right)$ & -20.8 & -12.3 & -20.1 \\
$\quad$ Switch & $\pi^{C}\left(t_{c}, t_{r}, c_{T}\right)$ & -76.2 & -50.0 & -75.0 \\
network & $\pi_{q}\left(t_{c}, t_{r}, c_{T}\right)$ & & & \\
per transaction $\left(\times 10^{-3}\right)$ & & & 35.0 & 20.8 \\
Welfare: & $W^{C}\left(t_{c}, t_{r}, c_{T}\right)$ & 20.8 & & \\
& & & & \\
\hline
\end{tabular}

Parameters: $\epsilon_{c}=3, \epsilon_{r}=2.2, \underline{b}_{c}=0.10, \underline{b}_{r}=0.09, c=0.28\left(c_{c}=c_{r}=0.14\right), c_{T}=0.32\left(c_{A}=c_{I}=0.02\right)$, $N=1000$; the number in italics indicates maximum social welfare.

numerically verified that $\bar{\epsilon} \approx 2.32$, so that for every $\epsilon_{c}>2.32$ we have that the "consumer" corner solution leads to maximum profits. Second, socially optimal demand for debit card payments is almost five times as high as in the double monopoly case. Clearly, debit card services are undersupplied in the latter case. However, by implementing the socially optimal prices Switch will incur operational losses. Negative profit margins will result, since $\epsilon_{c}>1$. Third, following condition (54), $\underline{b}_{c}=0.10 \leq c-\left(\epsilon_{r}-1\right)\left(c_{I}+c_{A}\right)=0.23$, and therefore socially optimal prices will be lower than the prices set by Switch.

\section{B. Balanced Budget Fees}

As shown above, for plausible parameter values, the debit card system will operate at a social loss by implementing socially optimal prices. Alternatively, we could optimize social welfare $W\left(t_{c}, t_{r}, c_{T}\right)$ under a balanced budget condition $t_{c}+t_{r}=c_{T}$. In this constrained setting, for the uniform case, we find 
Figure 5. "Corner" Social Welfare Functions

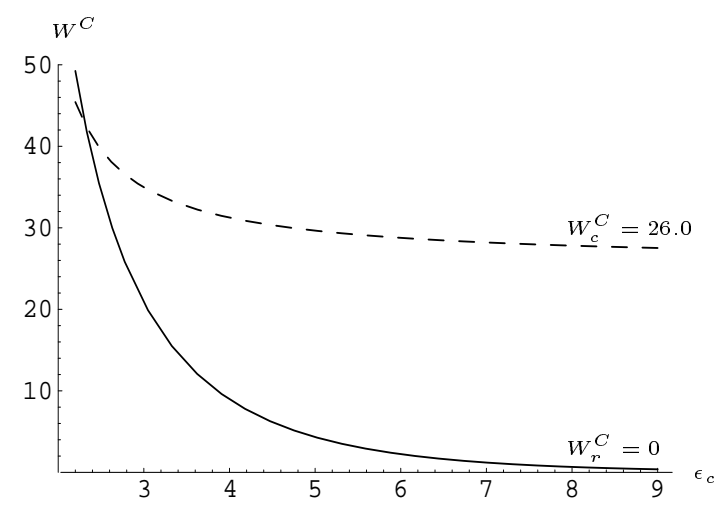

Note: The dotted line represents $W^{C}\left(\underline{b}_{c}, x_{r}, c_{T}\right)$, the straight line represents $W^{C}\left(x_{c}, \underline{b}_{r}, c_{T}\right)$.

$$
t_{c}^{U, b b}=\frac{1}{2}\left(\bar{b}_{c}-\bar{b}_{r}+c_{T}\right), \quad t_{r}^{U, b b}=\frac{1}{2}\left(\bar{b}_{r}-\bar{b}_{c}+c_{T}\right) .
$$

It is easy to show that these optimal balanced budget fees are lower than the fees set by Switch if and only if Switch makes positive profits in the monopolistic situation, i.e.

$$
\pi_{q}\left(t^{U, o}, c_{T}\right) \geq 0 \quad \text { if and only if } \quad t_{i}^{U, o} \geq t_{i}^{U, b b}, i=c, r \text {. }
$$

As before, for the constant elasticity case we find that constrained maximum social welfare is at one of the corner solutions, depending on the relative magnitude of the elasticities. In particular, it can be shown that there exists an $\bar{\epsilon} \geq \epsilon_{r}$ such that for $\epsilon_{c}>\bar{\epsilon}$, it holds that

$$
t_{c}^{C, b b}=\underline{b}_{c}, \quad t_{r}^{C, b b}=c_{T}-\underline{b}_{c} .
$$

Hence, if consumers are sufficiently price elastic, then the retailers end up paying for all the cost of the debit card network. Again, a similar result holds in the sense that the contrained socially optimal fee for the retailer is lower than the double monopoly fee if and only if Switch realizes a positive profit margin in the monopoly case. That is, in the constant elasticity case,

$$
\pi_{q}\left(t^{C, o}, c_{T}\right) \geq 0 \quad \text { if and only if } \quad t_{r}^{C, o} \geq t_{r}^{C, b b} .
$$

The continued example illustrates the impact of implementing balanced budget fees. 
Table 5. Balanced Budget Fees

\begin{tabular}{|c|c|c|c|}
\hline & & $\begin{array}{l}\text { Uniform } \\
\text { Interior Solution } \\
\end{array}$ & $\begin{array}{c}\text { Constant Elasticity } \\
\text { "Consumer" Corner Solution }\end{array}$ \\
\hline $\begin{array}{l}\text { Price: } \\
\text { consumer fee } \\
\text { retailer fee } \\
\text { total fee }\end{array}$ & $\begin{array}{l}t_{c} \\
t_{r} \\
t\end{array}$ & $\begin{array}{l}0.14 \\
0.18 \\
0.32\end{array}$ & $\begin{array}{l}0.10 \\
0.22 \\
0.32\end{array}$ \\
\hline $\begin{array}{l}\text { Elasticity: } \\
\text { consumer elasticity } \\
\text { retailer elasticity } \\
\text { total elasticity }\end{array}$ & $\begin{array}{l}\epsilon_{c}\left(t_{c}\right) \\
\epsilon_{r}\left(t_{r}\right) \\
\epsilon\left(t_{c}, t_{r}\right)\end{array}$ & $\begin{array}{l}2.3 \\
3.0 \\
5.3\end{array}$ & $\begin{array}{l}3.0 \\
2.2 \\
5.2\end{array}$ \\
\hline $\begin{array}{l}\text { Demand (in \%): } \\
\text { consumer demand } \\
\text { retailer demand } \\
\text { total demand }\end{array}$ & $\begin{array}{l}D_{c}\left(t_{c}, t_{r}\right) \\
D_{r}\left(t_{c}, t_{r}\right) \\
D\left(t_{c}, t_{r}\right)\end{array}$ & $\begin{array}{l}60.0 \\
40.0 \\
24.0\end{array}$ & $\begin{array}{c}100.0 \\
14.0 \\
14.0\end{array}$ \\
\hline $\begin{array}{l}\text { Profit: } \\
\text { Switch } \\
\text { network } \\
\text { per transaction }\left(\times 10^{-3}\right)\end{array}$ & $\begin{array}{l}\pi\left(t_{c}, t_{r}, c\right) \\
\pi\left(t_{c}, t_{r}, c_{T}\right) \\
\pi_{q}\left(t_{c}, t_{r}, c_{T}\right)\end{array}$ & $\begin{array}{l}9.6 \\
0.0 \\
0.0\end{array}$ & $\begin{array}{l}5.6 \\
0.0 \\
0.0\end{array}$ \\
\hline Welfare: & $W\left(t_{c}, t_{r}, c_{T}\right)$ & 14.4 & 32.7 \\
\hline
\end{tabular}

Parameters: $\underline{b}_{c}=0.10, \underline{b}_{r}=0.09, c=0.28\left(c_{c}=c_{r}=0.14\right), c_{T}=0.32\left(c_{A}=c_{I}=0.02\right), N=1000 ;$ uniform case: $\bar{b}_{c}=0.20, \bar{b}_{r}=0.24$; constant elasticity case: $\epsilon_{c}=3, \epsilon_{r}=2.2$.

Example I and II (continued):

As before, put the following common parameter values: $c=0.28\left(c_{c}=c_{r}=0.14\right)$, $c_{T}=0.32\left(c_{A}=c_{I}=0.02\right), \underline{b}_{c}=0.10, \underline{b}_{r}=0.09, N=1000$. For the uniform case we additionally set $\bar{b}_{c}=0.20$ and $\bar{b}_{r}=0.24$; for the constant elasticity case we additionally impose $\epsilon_{c}=3$ and $\epsilon_{r}=2.2$. Table 5 gives the results for both the uniform and the constant elasticity distribution.

Compared to the social optimum, since the total fee is higher, implementing balanced budget fees induces a drop in total demand for debit card payments in both cases. By definition, there is also a drop in social welfare, but in our example rather limited: a $16 \%$ drop in the uniform case and a 7\% drop in the constant elasticity case. As opposed to the unconstrained social optimum, Switch makes positive profits when implementing balanced budget fees. These profits are subsequently distributed among the banks. The issue remains how to distribute Switch's profits in such a way that no bank makes a loss. Further, observe that the balanced budget fees are lower or equal than the double-monopolistic fees, as seen from conditions (56) and (58). 


\section{Some Thoughts on System Competition}

Electronic payment systems typically have large set-up costs because of their relative capital intensity in terms of building high-technology electronic networks. Since duplication of these huge fixed costs does not seem desirable, actual network competition is often no viable option. ${ }^{16}$ The question arises how pure network activities can be separated from the provision of goods and services over the network, and whether competition is this latter segment is actually possible. The ability for a potential entrant to access the existing network becomes an important issue here. ${ }^{17}$ This type of competition is usually called "system" or "platform" competition, and can be illustrated within our theoretic model. Consider Figure 6, where a second network switch ("Switch 2") enters the arena, competing for consumers and retailers through the fees it sets.

Switch 2 is a system competitor that tries to capure business from Switch by signing up retailers for debit card services and facilitating electronic payment data transport. Analysing system competition in payment networks is complex. Therefore, in what follows, it is assumed that Switch 2 is able to freely access the existing authorisation network of banks in executing and processing debit card payments. In our setting, as in the previous sections, consumers and retailers are heterogenous. Their benefits of using a debit card (relative to cash) vary across the two populations and are private information. For convenience, we will assume that a consumer's gross benefits of using a debit card do not vary with which network switch - Switch ("S1") or Switch 2 ("S2") - the retailer is affiliated. Their debit cards, issued by the banks, are accepted by both systems. Retailers, in contrast, may have varying preferences across the two system competitors. Retailers may prefer to continue to do business with the incumbent player Switch even against higher prices, due to proven good standards and delivered high quality ("reputational effects"). The fees set by system competitor $j$ are $t_{c}^{j}$ for consumers and $t_{r}^{j}$ for retailers, $j=S_{1}, S_{2}$. A retailer with gross surplus $b_{r}^{j}$ from transacting on system $j$ is willing to do use this system if $b_{r}^{j}-t_{r}^{j}>b_{r}^{i}-t_{r}^{i}>0, i, j=S_{1}, S_{2}, i \neq j$. In the same spirit, a consumer is willing to buy from a retailer who is signed up with system competitor $j$ if $b_{c} \geq t_{c}^{j}$, but prefers to trade with a retailer who is using system $i$ if $t_{c}^{i}<t_{c}^{j}, i, j=S_{1}, S_{2}, i \neq j$.

Following Rochet and Tirole (2001), in order to analyze competition in this model, one needs to determine the demand functions of both sides of the market for asymmetric prices. Suppose

\footnotetext{
${ }^{16}$ In essence, network competition may cause a trade-off between static and dynamic efficiency. In the short term, consumers benefit from lower prices of services and goods, however, in the long run, low prices may lead to underinvestment in new network technologies. One runs the risk that newer, more advanced networks will not be able to gain critical mass.

${ }^{17}$ In the Netherlands, in the beginning of the 90s, commercial banks and Interpay invested huge amounts in building a highly secured and technologically advanced authorisation network, running considerable enterpreneurial risks during the starting-up phase. It seems obvious that a newcomer on the debit cards market who wants to make use of the network, should pay an "access fee" to compensate for these risks.
} 
Figure 6. System Competition in a Debit Card Network

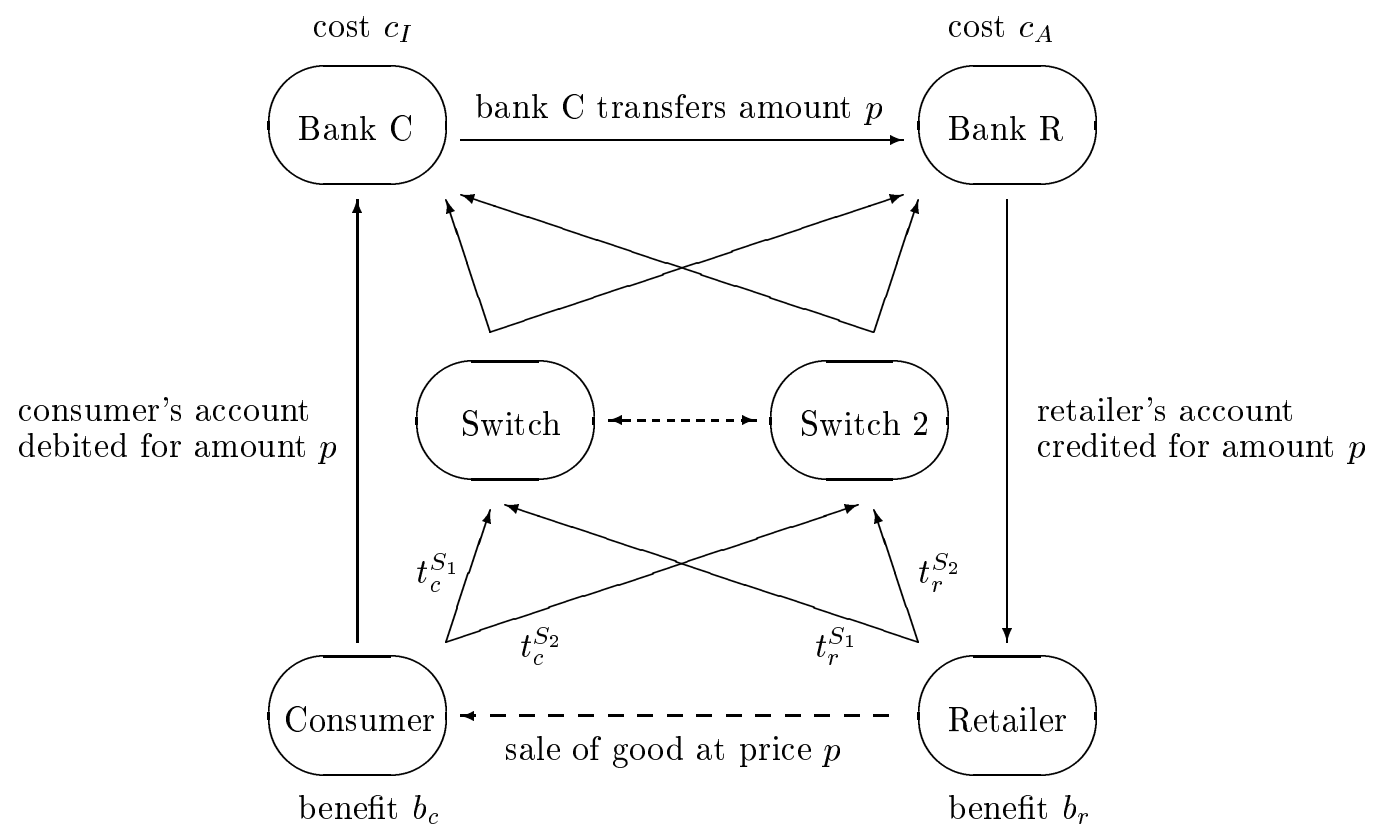

that the new competitor Switch 2 is cheaper for consumers: $t_{c}^{S_{2}}<t_{c}^{S_{1}}$. A consumer of type $b_{c}$ has three options: do not buy at all or use cash, only buy at a "Switch 2-affiliated" retail location, buy at "Switch-affiliated" and at "Switch 2-affiliated" retail locations. The first option is optimal when $b_{c}<t_{c}^{S_{2}}$. The choice between the other two options reflects a trade-off between forfeiting the benefits of card usage whenever the consumer enters a shop owned by a retailer that is not affiliated with Switch 2 and paying a higher fee at a retail location affiliated with the more expensive Switch. In this latter case, the consumer is said to "multihome": it buys both from Switch and Switch 2 affiliated retailers. This trade-off is characterized by a cut-off benefit level $\tilde{b}_{c}$, such that, for $b_{c} \geq \tilde{b}_{c}$, the consumer chooses to multihome, otherwise, for $b_{c}<\tilde{b}_{c}$, it will "singlehome" and only buys from Switch 2-affiliated retailers.

As in Rochet and Tirole (2001), one can show that consumers with low types do not use debit cards at all, consumers with high types buy from both Switch and Switch 2 affiliated retailers (these consumers multihome), and consumers with intermediate types only buy from retailers affiliated with the less expensive Switch 2. By undercutting its rival, Switch 2 induces some intermediate consumers to stop multihoming. This strategy is known as "steering". Hence, by undercutting prices, say from a symmetric price $t_{c}$ towards a price $t_{c}^{S_{2}}=t_{c}-\epsilon$, Switch 2 does not only attract new consumers (those with type $t_{c}-\epsilon \leq b_{c} \leq t_{c}$ ) but also steers former multihoming consumers (those with types $t_{c}^{S_{2}} \leq b_{c} \leq \tilde{b}_{c}$ ). 
From these theoretic observations one may derive the consumer's and retailer's demand as a function of asymmetric prices. Given these demand functions, the symmetric (interior) equilibrium is calculated. Rochet and Tirole (2001) find that the optimal pricing scheme is the same as in the monopoly case, except that one needs to modify the price-elasticities of demand to take into account the degree of multihoming and steering of consumers and retailers.

However, the authors only obtain results for the interior solution. The analysis in the previous sections indicates that also focusing on the corner solutions might be interesting since the resulting pricing arrangements are more in line with real-world observations. We leave this issue for future research.

\section{Conclusions}

Bringing about and maintaining efficient and reliable retail payment systems is important, since they play a crucial role in the exchange of goods, services and assets. However, payment systems and payment services are not free, but rather impose huge resource costs on society. It is therefore essential that payment systems satisfy some basic principles of economic efficiency. One important aspect of this concerns transparent and efficient pricing arrangements for electronic card payments.

Theoretical models may provide useful insights into the complexity of the multiplayer problems that payment activities pose. Using a theoretical model of electronic payment services, one can clarify how the two-sided character of the payment market affects optimal prices. In setting its transaction fees, the monopolistic network routing switch must make sure that both consumers and retailers "get on board". We have discussed how optimal prices in a two-sided payment market are related to price elasticities of demand. The optimal pricing structure very much depends on the choice of the underlying probability distribution describing the benefits of using debit cards across consumers and retailers. "Regular" log-concave demand functions suffer from the counterintuitive property that the more elastic side of the market is charged higher transaction fees. However, by analyzing so-called corner solutions, we are able to explain observed pricing strategies in the Netherlands. Under a constant elasticity of demand function, and assuming that consumer demand for debit card services is sufficiently more price elastic than retailer demand, an interesting phenomenon arises: the consumer side of the payment market is used to generate an increase in demand for debit card payments. The retailers pay the price in terms of a high fee, which could, in fact, be higher than the ordinary one-sided market monopoly price. This theoretical result nicely corresponds to current pricing arrangements in the Netherlands for debit cards. Dutch retailers pay a positive transaction fee for accepting debit card payments while consumers are not charged per transaction.

Further, when we analyze socially optimal pricing for electronic payment services, we find that our results remain qualitatively unchanged but that prices are lower than those set by the monopolistic network routing switch, inducing underprovision of debit card services. 
Consequently, by implementing socially optimal fees, the commercial banks who jointly own the payment network may face an operational loss. To overcome this lack of profitability, (government) subsidies, cross-selling, or imposing interchange fees might be needed to induce banks to participate in the electronic payment network. Alternatively, our analysis seems to indicate that having a payment system operate under a balanced budget restriction results in only a limited social welfare loss. 


\section{References}

Baxter, W., 1983, "Bank Interchange of Transactional Paper: Legal Perspectives", Journal of Law and Economics, Vol. 26, pp. 541-588.

Bolt, W., 2003, "Retail Payments in the Netherlands: Some Facts and Some Theory", Research Memorandum 722, De Nederlandsche Bank NV, Amsterdam, The Netherlands, http://www.dnb.nl.

Chang, H., and D. Evans, 2000, "The Competitive Effects of Collective Setting of Interchange Fees by Payment Card Systems", The Antitrust Bulletin (Fall), pp. 641-677.

European Commission, 2000, "Commission Plans to Clear Certain Visa Provisions, Challenge Others", Brussels, Press Release, October 16.

Gans, J., and S. King, 2001a, "The Neutrality of Interchange Fees in Payment Systems", Unpublished, University of Melbourne.

—_ 2001b, "Regulating Interchange Fees in Payment Systems", Unpublished, University of Melbourne.

Hotelling, H., 1929, "The Stability of Competition", Economic Journal, Vol. 39, pp. 41-57.

Humphrey, D., M. Kim, and B. Vale, 2001, "Realizing the Gains from Electronic Payments", Journal of Money, Credit, and Banking, Vol. 33, pp. 216-234.

Humphrey, D., L. Pulley, and J. Vessala, 2000, "The Check's in the Mail: Why the United States Lags in the Adoption of Cost-Saving Electronic Payments", Journal of Financial Services Research, Vol. 17, pp. 17-39.

Kreuger, M., 2001, "Interchange Fees in the Line of Fire", Unpublished, Institute for Prospective Technological Studies, Seville, Spain.

Rochet, J., and J. Tirole, 1999, "Cooperation among Competitors: The Economics of Payment Card Associations", CEPR Discussion Paper 2101, Centre for Economic Policy and Research.

—_, 2001, "Platform Competition in Two-Sided Markets", Unpublished, IDEI and GREMAQ, Toulouse.

Schmalensee, R., 2001, "Payments Systems and Interchange Fees", NBER Working Paper 8256, National Bureau for Economic Research.

Schwartz, M., and D. Vincent, 2002, "Vertical Control by Payment Networks", Working Paper 1, Georgetown University, Washington.

Tirole, J., 1989, The Theory of Industrial Organization (London: MIT Press, Second Edition).

Wright, J., 2001, "An Economic Analysis of a Card Payment Network", Unpublished, University of Auckland. 